\title{
A modified surface energy balance algorithm for land (M-SEBAL) based on a trapezoidal framework
}

\author{
Di Long ${ }^{1}$ and Vijay P. Singh ${ }^{1,2}$ \\ Received 28 February 2011; revised 23 November 2011; accepted 5 January 2012; published 23 February 2012.
}

[1] The surface energy balance algorithm for land (SEBAL) has been designed and widely used (and misused) worldwide to estimate evapotranspiration across varying spatial and temporal scales using satellite remote sensing over the past $15 \mathrm{yr}$. It is, however, beset by visual identification of a hot and cold pixel to determine the temperature difference $(d T)$ between the surface and the lower atmosphere, which is assumed to be linearly correlated with surface radiative temperature $\left(T_{\text {rad }}\right)$ throughout a scene. To reduce ambiguity in flux estimation by SEBAL due to the subjectivity in extreme pixel selection, this study first demonstrates that SEBAL is of a rectangular framework of the contextual relationship between vegetation fraction $\left(f_{\mathrm{c}}\right)$ and $T_{\mathrm{rad}}$, which can distort the spatial distribution of heat flux retrievals to varying degrees. End members of SEBAL were replaced by a trapezoidal framework of the $f_{\mathrm{c}}-T_{\text {rad }}$ space in the modified surface energy balance algorithm for land (M-SEBAL). The warm edge of the trapezoidal framework is determined by analytically deriving temperatures of the bare surface with the largest water stress and the fully vegetated surface with the largest water stress implicit in both energy balance and radiation budget equations. Areally averaged air temperature $\left(T_{\mathrm{a}}\right)$ across a study site is taken to be the cold edge of the trapezoidal framework. Coefficients of the linear relationship between $d T$ and $T_{\text {rad }}$ can vary with $f_{\mathrm{c}}$ but are assumed essentially invariant for the same $f_{\mathrm{c}}$ or within the same $f_{\mathrm{c}}$ class in M-SEBAL. SEBAL and M-SEBAL are applied to the soil moisture-atmosphere coupling experiment (SMACEX) site in central Iowa, U.S. Results show that M-SEBAL is capable of reproducing latent heat flux in terms of an overall root-mean-square difference of $41.1 \mathrm{~W} \mathrm{~m}^{-2}$ and mean absolute percentage difference of $8.9 \%$ with reference to eddy covariance tower-based measurements for three landsat thematic mapper/enhanced thematic mapper plus imagery acquisition dates in 2002. The retrieval accuracy of SEBAL is generally lower than M-SEBAL, depending largely on the selected extremes. Spatial distributions of heat flux retrievals from SEBAL are distorted to a certain degree due to its intrinsic rectangular framework.

Citation: Long, D., and V. P. Singh (2012), A modified surface energy balance algorithm for land (M-SEBAL) based on a trapezoidal framework, Water Resour. Res., 48, W02528, doi:10.1029/2011WR010607.

\section{Introduction}

[2] Evapotranspiration (ET), including evaporation from soil surfaces and vegetation transpiration, is a key component of the hydrologic cycle and controls the availability of water on the Earth's surface along with rainfall and runoff. In the context of a growing population and climate change, accurate monitoring of ET distribution at river basin, regional, and even continental scales is increasingly important for reasonably allocating and efficiently utilizing water resources, particularly over semiarid and arid areas. Traditional techniques of measuring ET, e.g., weighing lysimeter, energy balance Bowen ratio (EBBR) systems, and eddy

\footnotetext{
${ }^{1}$ Department of Biological and Agricultural Engineering, Texas A\&M University, College Station, Texas, USA.

${ }^{2}$ Department of Civil and Environmental Engineering, Texas A\&M University, College Station, Texas, USA.
}

Copyright 2012 by the American Geophysical Union 0043-1397/12/2011WR010607 covariance (EC) systems, are generally subject to field or landscape scales. Hydrologic budget calculations are often used to roughly estimate lumped ET for a watershed system. However, one cannot obtain detailed information regarding the spatial distribution of ET by these measurements or calculations. An accurate understanding of large-scale ET is therefore required for improving water use efficiency for agricultural crops and projecting end-of-season yield, allocating water resources within a river basin system, constraining recharge in groundwater simulations, providing important boundary conditions for numerical weather forecasting, detecting forest health and vulnerability to fire, and so forth [e.g., Anderson et al., 2007; Bastiaanssen et al., 2002; Norman et al., 2003].

[3] The advent of satellite remote sensing provides an opportunity to capture critical variables of surface properties and landscape characteristics for deriving large-scale ET. Tremendous efforts have been made to incorporate remotely sensed surface radiative temperature $\left(T_{\mathrm{rad}}\right)$ in combination with other critical variables, e.g., vegetation index 
(VI) and albedo, into ET modeling during the past three decades [Kalma et al., 2008]. These efforts have resulted in the development of a broad range of satellite-based ET models with varying degrees of complexity and mechanisms. The surface energy balance algorithm for land (SEBAL) has been developed and widely used to estimate ET at varying spatial and temporal scales over the past $15 \mathrm{yr}$ [Bastiaanssen et al., 1998, 2005; Pelgrum and Bastiaanssen, 1996]. However, the applicability and operability of SEBAL remain controversial in the operational ET estimation community due primarily to the visual identification of two critical extremes, i.e., the hot and cold pixels, involved in the calculation of sensible heat flux $(H)$.

[4] It is noted that a variant of SEBAL, i.e., mapping evapotranspiration at high-resolution with internalized calibration (METRIC), has been developed [Allen et al., 2007], in which some modifications to energy balance terms for hot and cold extremes in SEBAL were made and a socalled reference ET fraction method to extrapolate latent heat flux (LE) to daily ET was used. However, METRIC inherits substantially the key component of $H$ from SEBAL and relevant procedures for selecting the two anchor points.

[5] Many researchers and practitioners have explored the application of SEBAL/METRIC to estimate ET for improving water use efficiency, water resources allocation and management, as well as efficacies of distributed hydrologic models. However, a majority of these studies and applications appear to fall short of rigorous validation due in large part to the lack of expensive field instruments [e.g., Compaoré et al., 2008; Courault et al., 2009; Karatas et al., 2009; Li and Zhao, 2010; Wu et al., 2010; Yao et al., 2010]. Or, they compared daily ET estimates based on the assumption of fairly invariant evaporative fraction (EF) throughout a day derived at the satellite overpass with daily ET measurements from weighing lysimeters [e.g., Allen et al., 2007; Ramos et al., 2009] or from limited number of EBBR or EC towers [e.g., Folhes et al., 2009; Wang et al., 2009; Zwart and Bastiaanssen, 2007], or with daily ET calculations from the reference ET-crop coefficient method [e.g., Ahmed et al., 2010; Bashir et al., 2009; Bastiaanssen, 2000; Gao et al., 2008; Oberg and Melesse, 2006; Zwart et al., 2010]. Monthly, seasonal or longer timescale ET estimates were compared with counterparts from water balance approaches [e.g., Bastiaanssen et al., 2002; Long and Singh, 2010; Mohamed et al., 2004, 2006].

[6] Bastiaanssen et al. [2005] stated that the typical accuracy of SEBAL at field scale is $85 \%$ for $1 \mathrm{~d}$ and it increases to $95 \%$ on a seasonal basis. The annual ET estimates of large watersheds even show higher accuracy up to $96 \%$ on average. We suggest that as daily, monthly, or seasonal accumulated ET estimates are a function of both SEBAL-based EF or reference ET fraction at the satellite overpass and daily net radiation, errors involved in $H$ and LE estimates at the satellite overpass could be canceled out in the integrated ET estimates at a relatively longer timescale. In other words, even though the ET estimates show agreement with some integrated measurements or calculations on a daily or a longer timescale, there is still a possibility that the most critical outputs of $H$ and then LE at the image time involve large uncertainties. Furthermore, the spatial distribution of ET may be distorted due to the inadequacies of model physics of SEBAL.
[7] There are indeed some relatively rigorous studies addressing the evaluation of SEBAL by comparing SEBALbased estimates at the image time with measurements of EC or EBBR systems, or large aperture scintillometers [e.g., Kleissl et al., 2009; Marx et al., 2008; Singh et al., 2008; Teixeira et al., 2009]. Nevertheless, these studies seem to be less than adequate in examining errors in the model outputs from the perspective of model physics, e.g., the highly consistent overestimation of $H$ by Melesse and Nangia [2005] and Teixeira et al. [2009], and the consistent underestimation of $H$ by Kleissl et al. [2009], Marx et al. [2008], and Singh et al. [2008], were not well expounded. Or, all of the errors and uncertainties were presumably attributed to the two extremes and/or one-source parameterization scheme in SEBAL.

[8] Timmermans et al. [2007] performed an insightful comparison between SEBAL and two source energy balance (TSEB) [Norman et al., 1995] using the Southern Great Plains' 1997 and Monsoon' 1990 data sets. The meticulous selection of end members of $T_{\text {rad }}$ for one image acquisition date for five cases and a preliminary sensitivity analysis help with a greater understanding of SEBAL. However, this study mistakenly took $\mathrm{kB}^{-1}=2.3$ as a part of the SEBAL algorithm; in fact, SEBAL does not use a fixed $\mathrm{kB}^{-1}$ parameter, but rather takes the roughness length for heat transfer $\left(z_{\mathrm{oh}}\right)$ as $0.1 \mathrm{~m}$ [Bastiaanssen et al., 2002, 2005]. Therefore, Timmermans et al. [2007] appear to exaggerate the effect of $z_{\mathrm{oh}}$ on the resulting $H$ and LE estimates in SEBAL, attributing in part the errors to incorrect causes. French et al. [2005a] conducted a comparison between SEBAL and TSEB at the soil moisture-atmosphere coupling experiment (SMACEX) site in central Iowa, for one image acquisition day (DOY 182) using one pair of extreme pixels. They obtained a significantly larger $H$ estimate from SEBAL compared with those from the TSEB and EC towers. We suggest that a more complete picture of the performance of SEBAL can be obtained by increasing the number of quasi-hot and cold extremes and combinations thereof. Long et al. [2011] investigated the sensitivity of SEBAL to its inputs, domain size, and spatial resolution of satellite sensors, indicating that increases in temperatures of hot and/or cold extremes will decrease the resulting $H$ estimates and then increase the LE estimates. Likewise, decreases in temperatures of hot and/or cold extremes will increase the resulting $H$ estimates and then decrease the LE estimates. An increase in the available energy of the hot extreme will increase the $H$ estimates and then decrease the LE estimates.

[9] It is critically important to note that almost all studies pertaining to SEBAL, in particular those of the model developers [Allen et al., 2007; Bastiaanssen et al., 2010], recognize the key role of extremes in the resulting estimates; a large uncertainty in the model outputs could be introduced by differing extremes manually identified by the operator. The consensus on the difficulty of selecting appropriate extremes, compounded by limited ground-based measurements of surface fluxes which are rarely available in most developing countries, seems to hinder a greater understanding of the deficiencies of the model physics and a substantial improvement in this model.

[10] The objective of this study therefore is to systematically explore the deficiencies in the formulation of SEBAL, 
and develop a new framework to replace the intractable step of the selection of two extremes. Performance of the newly developed modified surface energy balance algorithm for land (M-SEBAL) is compared with SEBAL at the SMACEX site with a dense flux tower network, which provides an excellent data set for validating the two models and comparing and contrasting their advantages and limitations.

\section{Model Formulation}

\subsection{Model Formulation of SEBAL}

[11] The theoretical and computational basis of SEBAL can be found in the work of Bastiaanssen et al. [2002, 2005] and Allen et al. [2007]. In this model, LE is calculated as the residual of the energy balance equation:

$$
\mathrm{LE}=R_{\mathrm{n}}-G-H,
$$

where $R_{\mathrm{n}}$ is the net radiation $\left(\mathrm{W} \mathrm{m}^{-2}\right)$ and $G$ is the soil heat flux (W $\left.\mathrm{m}^{-2}\right) . R_{\mathrm{n}}-G$ can be defined as the available energy, $\Delta E\left(\mathrm{~W} \mathrm{~m}^{-2}\right)$. Partitioning of $\Delta E$ into $H$ and LE by either treating the landscape as a mixture of vegetation and soil or as separate components manifests the distinction between the one- and the two-source models. Both SEBAL and M-SEBAL pertain to the one-source model.

[12] $R_{\mathrm{n}}$ comprises two major components, the net shortwave radiation and the net long wave radiation, both of which depend largely on extraterrestrial radiation, atmospheric states and composition, and surface states and properties:

$$
\begin{aligned}
R_{\mathrm{n}} & =(1-\alpha) S_{\mathrm{d}}+\left(L_{\mathrm{d}}-L_{\mathrm{u}}\right)-(1-\varepsilon) L_{\mathrm{d}} \\
& =(1-\alpha) S_{\mathrm{d}}+\varepsilon \varepsilon_{\mathrm{a}} \sigma T_{\mathrm{a}}^{4}-\varepsilon \sigma T_{\mathrm{rad}}^{4},
\end{aligned}
$$

where $\alpha$ is the surface albedo (dimensionless), which can be retrieved using the algorithm proposed by Tasumi et al. [2008] for Landsat thematic mapper (TM)/enhanced thematic mapper plus $\left(\mathrm{ETM}^{+}\right)$imagery (there are a series of algorithms for retrieving $\alpha$ for varying satellite platforms). $S_{\mathrm{d}}$ is the downwelling shortwave radiation $\left(\mathrm{W} \mathrm{m}^{-2}\right) ; L_{\mathrm{d}}$ and $L_{\mathrm{u}}$ are the downwelling and upwelling long wave radiation $\left(\mathrm{W} \mathrm{m} \mathrm{m}^{-2}\right)$, respectively, which can be computed with the Stefan-Boltzmann law; $\varepsilon$ is the broad-band surface emissivity (dimensionless), which can be calculated with the equation by Tasumi [2003]. $\varepsilon_{\mathrm{a}}$ is the atmospheric emissivity (dimensionless), which is a function of air temperature $T_{\mathrm{a}}(\mathrm{K})$ and vapor pressure $e_{\mathrm{a}}(\mathrm{hPa})$ [Brutsaert, 1975]; $\sigma$ is the Stefan-Boltzmann constant $\left(5.67 \times 10^{-8} \mathrm{~W} \mathrm{~m}^{-2} \mathrm{~K}^{-4}\right)$; and $T_{\text {rad }}$ is the surface radiative temperature $(\mathrm{K})$, which can be derived from the thermal infrared band ( $\mathrm{s}$ ) for a specific satellite platform by a variety of algorithms, e.g., Landsat TM/ $\mathrm{ETM}^{+}$by Cristóbal et al. [2009] and moderate resolution imaging spectroradiometer (MODIS) by [Wan and $\mathrm{Li}$, 1997]. The formula for calculating $S_{\mathrm{d}}$ is given as

$$
S_{\mathrm{d}}=\frac{\mathrm{I}_{0}}{d^{2}} \cos \left(\theta_{\mathrm{s}}\right) \tau_{\mathrm{sw}}
$$

where $\mathrm{I}_{0}$ is the solar constant $\left(1367 \mathrm{~W} \mathrm{~m}^{-2}\right)$; $d$ is the EarthSun distance (dimensionless); $\theta_{\mathrm{s}}$ is the solar incidence angle (rad) with reference to the sloping surface (the flat surface is a specific case), which can be calculated with the formula by Allen et al. [2007] or Long et al. [2010]. And $\tau_{\text {sw }}$ is the broad-band atmospheric transmissivity (dimensionless), which can be calculated using a formula determined by atmospheric pressure, turbidity coefficient, precipitable water content in the atmosphere, and the solar incidence angle with reference to the flat surface [Allen et al., 2007].

[13] In SEBAL, $G$ is a function of $R_{\mathrm{n}}, T_{\mathrm{rad}}, \alpha$, and the normalized difference vegetation index (NDVI, dimensionless) given as

$$
G=R_{\mathrm{n}}\left(T_{\mathrm{rad}}-273.15\right)(0.0038+0.0074 \alpha)\left(1-0.98 \mathrm{NDVI}^{4}\right) .
$$

[14] The core component of most of satellite-based ET approaches is the $H$ scheme or the partitioning of $\Delta E$. In SEBAL, $H$ is calculated as

$$
\begin{gathered}
H=\rho \mathrm{c}_{\mathrm{p}} \frac{d T}{r_{\mathrm{ah}}}=\rho \mathrm{c}_{\mathrm{p}} \frac{a T_{\mathrm{rad}}+b}{r_{\mathrm{ah}}}, \\
r_{\mathrm{ah}}=\frac{1}{\mathrm{k} u_{*}}\left[\ln \left(\frac{z_{2}}{z_{1}}\right)-\psi_{\mathrm{h}(2)}+\psi_{\mathrm{h}(0.1)}\right], \\
u_{*}=\mathrm{k} u_{200} /\left[\ln \left(\frac{200}{z_{\mathrm{om}}}\right)-\psi_{\mathrm{m}(200)}\right],
\end{gathered}
$$

where $\rho$ is the air density $\left(\mathrm{kg} \mathrm{m}^{-3}\right)$; $\mathrm{c}_{\mathrm{p}}$ is the specific heat of air at constant pressure $\left(\mathrm{J} \mathrm{kg}^{-1} \mathrm{~K}^{-1}\right)$; $d T$ is the difference between the aerodynamic temperature and the air temperature $(\mathrm{K})$, which is linearly related to $T_{\mathrm{rad}}$ in SEBAL. $a$ (dimensionless) and $b(\mathrm{~K})$ are coefficients of the linear relationship throughout a scene, which are derived by hot and cold extremes selected from the satellite image; $r_{\mathrm{ah}}$ is the aerodynamic resistance for heat transfer $\left(\mathrm{s} \mathrm{m}^{-1}\right) ; \mathrm{k}$ is the von Karman constant $(0.41) ; u_{*}$ is the friction velocity $\left(\mathrm{m} \mathrm{s}^{-1}\right) ; z_{2}(=2 \mathrm{~m})$ and $z_{1}(=0.1 \mathrm{~m})$ are the heights above the zero plane displacement of the vegetation where the endpoints of $d T$ are defined. The fixed value of $z_{1}$ (i.e., the roughness length for heat transfer, $z_{\mathrm{oh}}$, in other models) allows SEBAL to estimate $r_{\text {ah }}$ without accounting for differences in $z_{\text {oh }}$ throughout an image which is quite difficult to obtain. $z_{\text {om }}$ is the roughness length for momentum transfer $(\mathrm{m})$, which can be related to leaf area index (LAI) or NDVI [e.g., Bastiaanssen, 2000; Tasumi, 2003]; $u_{200}$ is the wind velocity at an assumed blending height $(=200 \mathrm{~m})$, which can be inferred by wind velocity at a weather station. It is noted that SEBAL assumes $u_{200}$ to be constant across a scene, which necessitates a relatively steady meteorological condition; $\psi_{\mathrm{h}(2)}$ and $\psi_{\mathrm{h}(0.1)}$ are stability correction factors for heat transfer at the heights of $z_{2}$ and $z_{1}$, respectively; and $\psi_{\mathrm{m}(200)}$ is the stability correction factor for momentum transfer at the $200 \mathrm{~m}$ height. These stability correction factors can be calculated using formulas proposed by Paulson [1970] and Webb [1970].

[15] Coefficients $a$ and $b$ are constant throughout a scene, which are determined by the characteristic variables for two anchor points selected from the satellite image. For the hot extreme, LE is zero and $H$ is therefore equal to its 
available energy, i.e., $R_{\mathrm{n}, \text { hot }}-G_{\mathrm{hot}}$ or $\Delta E_{\mathrm{hot}}$; for the cold extreme, $H$ is zero. In terms of these definitions, $a$ and $b$ can be explicitly expressed as

$$
\begin{gathered}
a=\frac{r_{\mathrm{ah}, \mathrm{hot}}}{\rho_{\mathrm{hot}} \mathrm{c}_{\mathrm{p}}} \times \frac{R_{\mathrm{n}, \mathrm{hot}}-G_{\mathrm{hot}}}{T_{\mathrm{rad}, \mathrm{hot}}-T_{\mathrm{rad}, \mathrm{cold}}}, \\
b=-a T_{\text {rad,cold }},
\end{gathered}
$$

where the subscripts hot and cold are referred to as respective extremes. As all stability correction factors are also a function of $H$ involved in the Monin-Obukhov length, equations (5)-(9) should be solved in an iterative manner. After $a$ and $b$ are derived, they constitute inputs of equations (5)-(7) to calculate $H$ for the remaining pixels.

[16] Long et al. [2011] performed a systematic study on the sensitivity of SEBAL, indicating that $T_{\text {rad,hot, }}, T_{\text {rad,cold, }}$, and $R_{\mathrm{n} \text {,hot }}$ (or $\Delta E_{\mathrm{hot}}$ ) are the most critical variables in determining $a$ and $b . T_{\text {rad }}$ is the most significant variable in determining $H$ for the remaining pixels given a pair of $a$ and $b$. After $H$ for all pixels is calculated, LE can be calculated using equation (1). It is important to note that the calculation of $H$ in SEBAL is not conditioned by $\Delta E$; a possibility exists that the $H$ estimates for certain pixels are larger than $\Delta E$ due to unrealistic estimates of $d T$ (i.e., $a$ and $b$ ) for areas with low vegetation fraction $\left(f_{\mathrm{c}}\right)$, which will be further discussed in section 5.5.

\subsection{Trapezoidal Framework of M-SEBAL}

[17] The contextual relationship between $f_{\mathrm{c}}$ and $T_{\mathrm{rad}}$ forms the foundation of triangle/trapezoid models of estimating EF or a water deficit index [e.g., Carlson, 2007; Gillies et al., 1997; Jiang and Islam, 2001; Moran et al., 1994; Price, 1990]. Modifications to SEBAL start with interpretations of the $f_{\mathrm{c}}-T_{\mathrm{rad}}$ space.

[18] Figure 1 is a sketch of the scatterplot of $f_{\mathrm{c}}$ and $T_{\mathrm{rad}}$ and its theoretical boundaries. The scatterplot of $f_{\mathrm{c}}$ and $T_{\mathrm{rad}}$ for a given study site would constitute essentially a trapezoid $\mathrm{AB}^{\prime} \mathrm{CD}$ if it can cover a broad range of surface water content and $f_{\mathrm{c}}$. It is noted that triangle models necessitate the specification of limiting edges (warm and cold edges where $\mathrm{EF}$ achieves minimum or maximum values for a full range of $f_{\mathrm{c}}$ ) directly from data points of the scatterplot. The proposed use of the trapezoidal framework in M-SEBAL deviates from SEBAL and triangle models in analytically deriving the theoretical boundaries of EF without specifying extreme pixels or limiting edges from the satellite image. Specifying extreme pixels or limiting edges directly from satellite images could suffer from domain dependence and resolution dependence as expounded by Long et al. [2011].

[19] For trapezoid $\mathrm{AB}^{\prime} \mathrm{CD}$, point $\mathrm{A}\left(f_{\mathrm{c}}=0, T_{\mathrm{rad}}=T_{\mathrm{s}, \max }\right)$ represents the bare surface with the largest water stress, i.e., $\mathrm{EF}=0$, point $\mathrm{B}^{\prime}\left(f_{\mathrm{c}}=0, T_{\mathrm{rad}}=T_{\mathrm{s}, \min }\right)$ represents the bare surface without water stress, i.e., $\mathrm{EF}=1$, point $\mathrm{C}\left(f_{\mathrm{c}}=1\right.$, $\left.T_{\mathrm{rad}}=T_{\mathrm{c}, \mathrm{min}}\right)$ represents the fully vegetated surface without water stress, i.e., $\mathrm{EF}=1$, and point $\mathrm{D}\left(f_{\mathrm{c}}=1, T_{\mathrm{rad}}=T_{\mathrm{c}, \max }\right)$ represents the fully vegetated surface with the largest water stress, i.e., nearly complete stomatal closure and $\mathrm{EF}=0$ [e.g., Moran et al., 1994; Stisen et al., 2008; Tang et al., 2010]. Side $\mathrm{AD}$ is called the warm edge of the $f_{\mathrm{c}}-T_{\text {rad }}$ space,

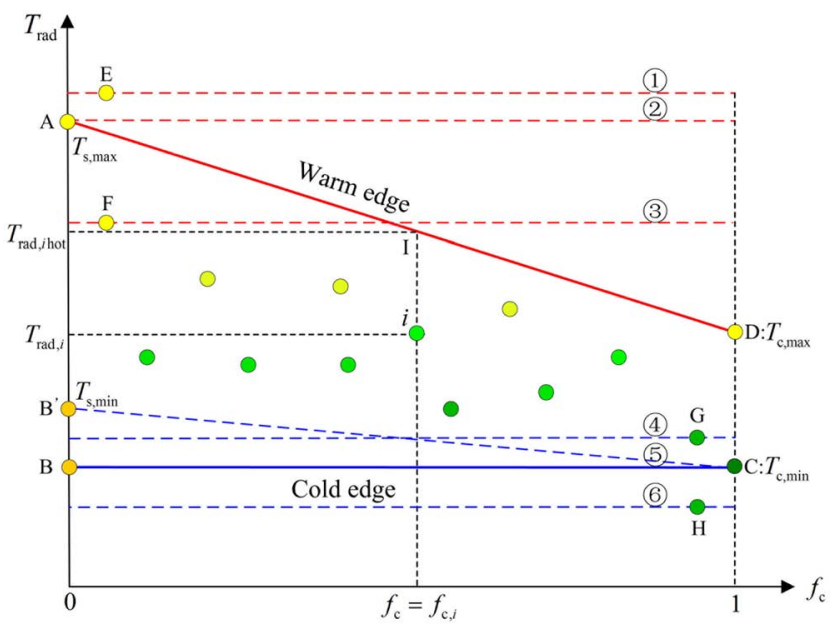

Figure 1. A sketch of the scatterplot of remotely sensed $f_{\mathrm{c}}$ and $T_{\text {rad }}$. Colored circles represent surfaces/pixels with varying $f_{\mathrm{c}}$ and $T_{\mathrm{rad}}$. Trapezoid $\mathrm{AB}^{\prime} \mathrm{CD}$ represents the real physical limits of the $f_{\mathrm{c}}-T_{\text {rad }}$ space. Point $\mathrm{A}$ represents the bare surface with the largest water stress (i.e., $\mathrm{EF}=0$ ), point $\mathrm{B}^{\prime}$ represents the bare surface without water stress (i.e., $\mathrm{EF}=1$ ), point $\mathrm{C}$ represents the fully vegetated surface without water stress (i.e., $\mathrm{EF}=1$ ), and point $\mathrm{D}$ represents the fully vegetated surface with the largest stress (i.e., $\mathrm{EF}=0$ ). Trapezoid ABCD represents the operationally simplified trapezoidal framework in M-SEBAL, in which point B represents the bare surface without water stress. Side $\mathrm{AD}$ is the warm edge representing surfaces of $\mathrm{EF}=0$ for a full range of $f_{\mathrm{c}}$, and side $\mathrm{BC}$ is the horizontal cold edge representing surfaces of $\mathrm{EF}=1$ for a full range of $f_{\mathrm{c}}$. Red dashed lines (1-3) represent hot edges possibly selected for SEBAL, corresponding to points E, A, and F. Blue dashed lines (4-6) represent cold edges, corresponding to points $\mathrm{G}, \mathrm{C}$, and $\mathrm{H}$.

i.e., $\mathrm{EF}$ is zero for surfaces on this edge. Side $\mathrm{B}^{\prime} \mathrm{C}$ is referred to as the cold edge of the $f_{\mathrm{c}}-T_{\text {rad }}$ space, i.e., surfaces on this edge are at equilibrium ET rates.

[20] Trapezoid $\mathrm{AB}^{\prime} \mathrm{CD}$ is also referred to as the theoretical envelope of the $f_{\mathrm{c}}-T_{\text {rad }}$ space. As vertices $\mathrm{B}^{\prime}$ and $\mathrm{C}$ of trapezoid $\mathrm{AB}^{\prime} \mathrm{CD}$ appear difficult to determine in some cases because of the need for on-site $R_{\mathrm{n}}$, vapor pressure deficit, and $T_{\mathrm{a}}$ measurements for the two extremes [Moran et al., 1994]. Especially over large areas where extreme surfaces cannot be easily identified from either field investigations or satellite images, here trapezoid $\mathrm{AB}^{\prime} \mathrm{CD}$ is simplified as trapezoid ABCD in M-SEBAL, where side BC is a horizontal cold edge of the $f_{\mathrm{c}}-T_{\text {rad }}$ space, with the aim to make the ET estimation more feasible without significantly compromising accuracy in practice. In M-SEBAL, cold edge $\mathrm{BC}$ is taken as the air temperature (i.e., $T_{\mathrm{s}, \min }=T_{\mathrm{c}, \min }$ $\left.=T_{\mathrm{a}}\right)$ at the image time, given the extreme case that the temperature gradient between the near surface and the lower atmosphere tends to be zero. The use of averaged inland water temperatures may be an alternative to prescribe the cold edge as shown in [e.g., Jiang et al., 2009].

[21] The use of the horizontal cold edge is intended to obviate poor demarcation of cold edges, which is often 
incurred by erroneous $T_{\text {rad }}$ retrievals due to cloud and/or terrain effects [e.g., Carlson, 2007; Gillies et al., 1997]. It is noted that the use of $T_{\mathrm{a}}$ to substitute for the theoretical cold edge $\mathrm{B}^{\prime} \mathrm{C}$ would overestimate surface temperatures of the wettest surfaces due to the presence of advection or an underestimate of surface temperatures over low $f_{\mathrm{c}}$ surfaces without water stress. This treatment is, however, an operational way to demarcate the lower boundary of the $f_{\mathrm{c}}-T_{\mathrm{rad}}$ space. We will further discuss the model advantages and limitations in section 6. Determination of vertices $\mathrm{A}$ and $\mathrm{D}$ (i.e., $T_{\mathrm{s}, \max }$ and $T_{\mathrm{c}, \max }$ ) will be illustrated in section 2.6.

[22] It is important to state that the trapezoidal framework involved in M-SEBAL serves as the theoretical boundaries of the $f_{\mathrm{c}}-T_{\text {rad }}$ space. The analytically derived highest temperatures (the warm edge) can be potentially achieved for the driest surfaces given certain meteorological conditions and surface characteristics. This concept of the theoretical warm boundary can be analogous to surfaces evaporating at potential rates. These extreme warm/cold surfaces might not exist or be detected by satellite images or field investigations across a scene, but they indeed provide a metric for confining $\mathrm{EF} / \mathrm{ET}$ values for a majority of surfaces/pixels with generic $T_{\text {rad }}$ values, functioning as a role of boundary conditions for a range of ET models.

\subsection{Rectangular Framework and Essential Form of EF in SEBAL}

[23] In SEBAL, there are three possibilities that the hot pixel is selected: point E (Figure 1) whose $T_{\text {rad }}$ is larger than point $\mathrm{A}$, point $\mathrm{A}$, and point $\mathrm{F}$ whose $T_{\text {rad }}$ is lower than point A. Similarly, the cold pixel is likely to be identified as point $\mathrm{G}, \mathrm{C}$, or $\mathrm{H}$, where the $T_{\mathrm{rad}}$ of $\mathrm{G}$ is larger than $T_{\mathrm{c}, \min }$ and the $T_{\mathrm{rad}}$ of $\mathrm{H}$ is smaller than $T_{\mathrm{c}, \mathrm{min}}$.

[24] For any combination of one hot pixel and one cold pixel, the two extreme pixels with constant $T_{\text {rad }}$ values could be analogous to two horizontal extreme edges throughout a scene, because the two extremes will not vary with $f_{c}$, forming a "rectangular" framework. All $T_{\text {rad }}$ values of pixels will be compared with $T_{\text {rad,hot }}$ and $T_{\text {rad,cold }}$ through coefficients $a$ and $b$ in order to deduce the $d T$ values for each pixel. EF from SEBAL for a given class $i$ of $f_{\mathrm{c}}$ can be written as

$$
\mathrm{EF}_{i}=\frac{\Delta E_{i}-H_{i}}{\Delta E_{i}}=1-\frac{\rho \mathrm{c}_{\mathrm{p}}}{\Delta E_{i}} \times \frac{a T_{\mathrm{rad}}+b}{r_{\mathrm{ah}, i}},
$$

where $\mathrm{EF}_{i}$ is $\mathrm{EF}$ for a pixel at a given $f_{\mathrm{c}}$ value or $f_{\mathrm{c}}$ at class $i, f_{\mathrm{c}, i} ; \Delta E_{i}$ is the available energy $\left(\mathrm{W} \mathrm{m}^{-2}\right)$ for the pixel at $f_{\mathrm{c}, i}$; and $r_{\mathrm{ah}, i}$ is the aerodynamic resistance $\left(\mathrm{s} \mathrm{m}^{-1}\right)$ at $f_{\mathrm{c}, i}$. For unraveling the essential relationship between $T_{\text {rad }}$ and $\mathrm{EF}_{i}$ in SEBAL, the variation in $\mathrm{EF}_{i}$ with $T_{\text {rad }}$ for $f_{\mathrm{c}}=0.2$, 0.4 , and 0.6 was simulated. $f_{\mathrm{c}}$ was retrieved using the formula and its parameters developed by Li et al. [2005] (see equation (A1)). It is noted that for the same $f_{\mathrm{c}}$ value or the same class of $f_{\mathrm{c}, i}$, a variation in $r_{\mathrm{ah}, i}$ can be negligible because $r_{\mathrm{ah}, i}$ is a function $z_{\mathrm{om}}$ and $u_{200}$ in SEBAL; both play a negligible role in determining $H$ [Long et al., 2011]. For the same $f_{\mathrm{c}, i}$, variables such as NDVI, $h_{\mathrm{c}}$, and consequently, $z_{\text {om }}$, remain essentially identical. $\Delta E_{i}$ is partly determined by $T_{\mathrm{rad}}$ in the calculation of $L_{\mathrm{u}}$ and $G$. However, the magnitudes of $L_{\mathrm{u}}$ and $G$ are both relatively small compared with the shortwave radiation component.
[25] Figure 2 shows that $\mathrm{EF}_{i}$ from SEBAL is highly correlated with $T_{\text {rad }}$, suggesting a quasi-linear relationship, and $\mathrm{EF}_{i}$ decreasing with increasing $T_{\text {rad }}$ EF from the triangle models is linearly correlated with $T_{\text {rad }}$ for each class $i$ of $f_{\mathrm{c}}$ :

$$
\mathrm{EF}_{i} \propto \frac{T_{\mathrm{rad} i \text { max }}-T_{\mathrm{rad}}}{T_{\mathrm{rad} i \text { max }}-T_{\mathrm{rad} i \text { min }}},
$$

where $T_{\text {radi,max }}$ and $T_{\text {radi,min }}$ are the temperatures of the extreme edges at class $i$ of $f_{\mathrm{c}}$. It is revealed that SEBAL is intrinsically of a similar form of $\mathrm{EF}_{i}$ as the triangle models. The only marked difference between SEBAL and the triangle models lies in the specification of extreme pixels or limiting edges which fundamentally determine the slope of the linear/quasi-linear variation in $\mathrm{EF}_{i}$ with $T_{\text {rad }}$.

\subsection{Uncertainty in SEBAL}

[26] SEBAL is beset by the selection of extremes from satellite images [e.g., Choi et al., 2009; French et al., 2005a; Timmermans et al., 2007]. As shown in Figure 1, each selected extreme essentially forms a limiting edge of its rectangular framework, with points $\mathrm{E}, \mathrm{A}, \mathrm{F}, \mathrm{G}, \mathrm{C}$, and $\mathrm{H}$ corresponding to the horizontal limiting edges of $1-6$, respectively. EF from SEBAL of cold edges $4-6$ is equal to 1 in terms of equations (8)-(10). The EF of hot edges 1-3 starts with 0 at points $\mathrm{E}, \mathrm{A}$, and $\mathrm{F}$, respectively, and will not greatly deviate from 0 as long as $\Delta E_{\text {hot }} \times r_{\text {ah,hot }}$ does not deviate greatly from $\Delta E_{i} \times r_{\mathrm{ah}, i}$ based on equations (8)-(10). It is important to state here that the rectangular framework intrinsic in SEBAL seems to be less than satisfactory in approximating trapezoid $\mathrm{AB}^{\prime} \mathrm{CD}$, which could distort the boundary conditions of $\mathrm{EF}$, and subsequently result in an

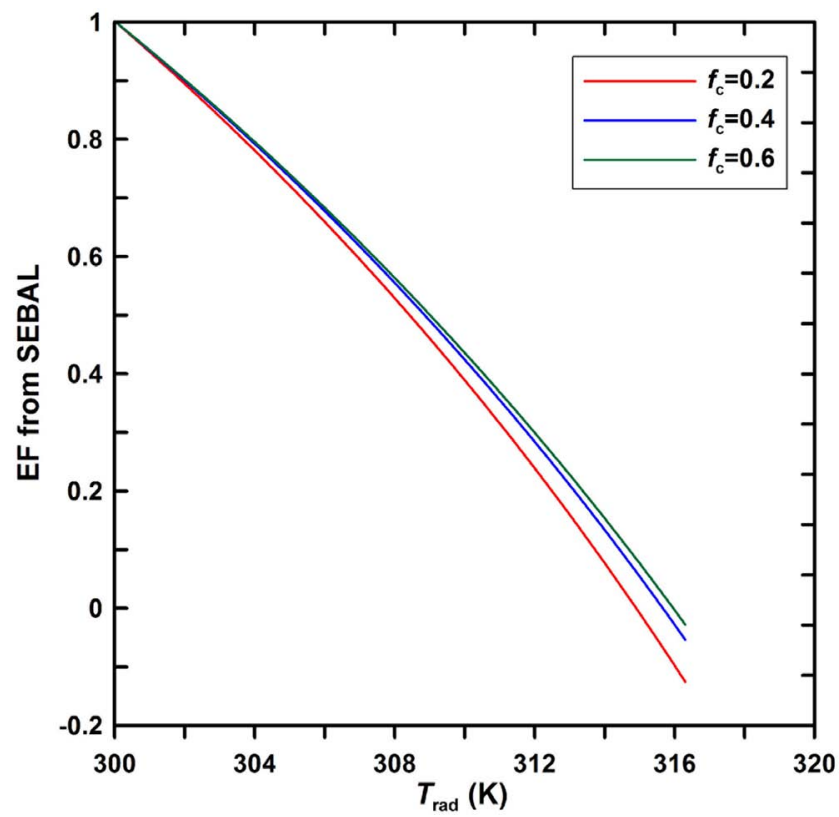

Figure 2. Variation in EF with $T_{\text {rad }}$ in SEBAL for $f_{\mathrm{c}}$ is equal to $0.2,0.4$, and 0.6 , respectively, given coefficients $a$ $(=0.27)$ and $b(=-80.35 \mathrm{~K})$ derived from a hot pixel with $T_{\text {rad,hot }}=316.3 \mathrm{~K}$ and a cold pixel with $T_{\text {rad,cold }}=300.1 \mathrm{~K}$ selected from the SMACEX site on DOY 174. Averaged $\Delta E_{i}$ and $r_{\mathrm{ah}, i}$ for each $f_{\mathrm{c}}$ were also derived to facilitate the simulation. 
unrealistic spatial distribution of the $H$ and LE estimates, especially for surfaces/pixels with $T_{\text {rad }}$ values surrounding the boundaries of trapezoid $\mathrm{AB}^{\prime} \mathrm{CD}$.

[27] Recall that with an increase in $T_{\text {rad,hot }}$ and/or $T_{\text {rad,cold }}$ in SEBAL, the $H$ estimates will decrease and then the LE estimates will increase. With a decrease in $T_{\text {rad,hot }}$ and/or $T_{\text {rad,cold }}$, the $H$ estimates will increase and consequently the LE estimates will decrease [Long et al., 2011]. Assume that trapezoid $\mathrm{ABCD}$ can represent the realistic boundaries of EF across the $f_{\mathrm{c}}-T_{\text {rad }}$ space and the realistic cold edge, i.e., cold edge 5 , can be correctly selected. In this case, if hot edge 1 is selected, it will result in a consistent overestimation of the upper boundary compared with the theoretical warm edge $\mathrm{AD}$, thereby resulting in the underestimation of $H$ and then an overestimation of LE. Furthermore, the discrepancies will be exacerbated with increasing $f_{\mathrm{c}}$. If hot edge 2 is selected, even though hot extreme $\mathrm{A}$ at $f_{\mathrm{c}}=0$ is accordant with the realistic one, the hot edge is generally over the warm edge $\mathrm{AD}$, yet causing an underestimation of $H$ and consequently an overestimation of LE. Particular attention needs to be paid to hot edge 3 that if $f_{\mathrm{c}}$ is less than the intersection of warm edge $\mathrm{AD}$ and hot edge 3 , the rectangular framework tends to overestimate $H$ and then underestimate LE; however, when exceeding the intersection, $H$ would be underestimated as in the previous two cases.

[28] Likewise, assume that cold edge 6 is identified. If hot edge 1 or 2 is selected, an overestimation of $H$ due to a lower cold edge compared with cold edge $\mathrm{BC}$, and an underestimation of $H$ due to a higher hot edge compared with warm edge $\mathrm{AD}$ could be offset. If hot edge 3 is identified, under the condition of $f_{\mathrm{c}}$ less than the intersection of hot edge 3 and warm edge $\mathrm{AD}, H$ could be overestimated; when $f_{\mathrm{c}}$ is larger than the intersection, the overestimation of $H$ would be alleviated due to hot edge 3 being over warm edge AD.

[29] Moreover, assume that cold edge 4 is identified. If hot edge 1 or 2 is selected, the rectangular framework is generally shifted upward, thereby resulting in an underestimation of $H$ and an overestimation of LE. If hot edge 3 is selected, the overestimation of $H$ due to a lower hot extreme and the underestimation of $H$ due to a higher cold extreme before the intersection of warm edge $\mathrm{AD}$ and hot edge 3 appear to be compensating. But after $f_{\mathrm{c}}$ exceeds the intersection, this case tends to underestimate $H$ and consequently overestimate LE. Over- or underestimation of heat fluxes depends largely on the relative magnitudes of discrepancy between the selected extremes and the corresponding theoretical extremes for certain $f_{\mathrm{c}}$ and $T_{\text {rad }}$ ranges.

[30] In summary, for any combination of selected extremes in SEBAL, the two horizontal extremes seem to distort the realistic distribution of heat fluxes to varying degrees for a certain range of $f_{\mathrm{c}}$. The rectangular framework intrinsic in SEBAL can result in overestimation or underestimation of fluxes incurred by uncertain extremes selected by the operator from satellite images. The magnitude of discrepancy between the resulting flux estimates and the truth depends largely on the relative differences between the horizontal extremes and the theoretical boundaries.

\subsection{Formulation of M-SEBAL}

[31] M-SEBAL has the same formulation of $R_{\mathrm{n}}$ and $G$ as SEBAL. It is noted that most of satellite-based ET models share the same formulation of $R_{\mathrm{n}}$. The most significant attribute or difference involved in these models rests on the formulation of $H$. As Norman et al. [2006] indicated, several linear relationships between $T_{\text {rad }}$ and $d T$ with significantly different slopes can, in fact, exist within a given landscape. Here M-SEBAL substitutes the trapezoidal framework $\mathrm{ABCD}$ for the rectangular framework intrinsic in SEBAL. It is assumed that coefficients $a$ and $b$ vary with $f_{\mathrm{c}}$ but remain fairly invariant for the same $f_{\mathrm{c}}$ or within the same $f_{\mathrm{c}}$ class, $i$, given as

$$
\begin{gathered}
a_{i}=\frac{r_{\mathrm{ah} i, \mathrm{hot}}}{\rho_{i \mathrm{hot}} \mathrm{c}_{\mathrm{p}}} \times \frac{R_{\mathrm{n} i, \mathrm{hot}}-G_{\text {ihot }}}{T_{\mathrm{rad} i \text { hot }}-T_{\mathrm{rad} i, \mathrm{cold}}}, \\
b_{i}=-a_{i} T_{\mathrm{rad} i, \mathrm{cold}},
\end{gathered}
$$

where subscript $i$ denotes class $i$ of $f_{\mathrm{c}}$. The other variables in equations (12) and (13) are the corresponding characteristic variables for hot or cold extremes on the theoretical warm (side AD) or cold edge (side BC). Pixels with the same $f_{\mathrm{c}}$ value or within class $f_{\mathrm{c}, i}$ use $a_{i}$ and $b_{i}$ to infer their temperature gradient $d T_{i}$ and subsequently calculate $H$.

[32] In equation (12), the aerodynamic resistance of point $\mathrm{I}$ in Figure $1, r_{\mathrm{ah}} i$,hot , can be determined using $z_{\mathrm{om}}$ specific for $f_{\mathrm{c}, i}$, and $u_{200}$, which is deemed constant across an image. The air density of point I can also be readily specified. $T_{\text {radi,hot }}$ and $T_{\text {radi,cold }}$ can be located on the theoretical warm and cold edges at $f_{\mathrm{c}}=f_{\mathrm{c}, i}$. Determination of warm edge $\mathrm{AD}$ will be illustrated in section 2.6. The available energy of the hot extreme at $f_{\mathrm{c}, i}$, i.e., $R_{\mathrm{n} i \text {,hot }}-G_{i \text { hot }}\left(\Delta E_{i \text {,hot }}\right)$, can be determined by the lower envelope of the $f_{\mathrm{c}}-\Delta E$ space at $f_{\mathrm{c}}=f_{\mathrm{c}, i}$, considering that for the extremely dry surfaces, i.e., $\mathrm{EF}=0$, the largest $T_{\text {rad }}$ contributes to relatively large outgoing long wave radiation; the extremely dry surfaces often show relatively large albedo, which contributes to relatively small net shortwave radiation; and the largest $T_{\text {rad }}$ contributes to the largest $G$ for the same $f_{\mathrm{c}, i}$. All three contributions would result in the smallest $\Delta E_{i \text {,hot }}$ for the hot extreme at $f_{\mathrm{c}, i}$; thereby, we take the lower rather than the upper envelope of the $f_{\mathrm{c}}-\Delta E$ space.

\subsection{Determination of Theoretical Boundaries of the Trapezoidal Framework}

[33] The theoretical warm edge of trapezoid ABCD is determined by solving for the $T_{\text {rad }}$ values of the bare surface with the largest water stress [Nishida et al., 2003] and a fully vegetated surface with the largest water stress (i.e., point A and $\mathrm{D}$ in Figure 1), implicit in both radiation budget and energy balance equations. Rewriting the radiation budget and energy balance equations for bare surfaces results in

$R_{\mathrm{n}, \mathrm{s}}=\left(1-\alpha_{\mathrm{s}}\right) S_{\mathrm{d}}+\varepsilon_{\mathrm{s}} L_{\mathrm{d}}-L_{\mathrm{u}}=\left(1-\alpha_{\mathrm{s}}\right) S_{\mathrm{d}}+\varepsilon_{\mathrm{s}} \varepsilon_{\mathrm{a}} \sigma T_{\mathrm{a}}^{4}-\varepsilon_{\mathrm{s}} \sigma T_{\mathrm{s}}^{4}$,

$$
R_{\mathrm{n}, \mathrm{s}}-G=H_{\mathrm{s}}+\mathrm{LE}_{\mathrm{s}}=\rho \mathrm{c}_{\mathrm{p}}\left(\frac{T_{\mathrm{s}}-T_{\mathrm{a}}}{r_{\mathrm{a}, \mathrm{s}}}\right)+\mathrm{LE}_{\mathrm{s}},
$$

where $R_{\mathrm{n}, \mathrm{s}}$ is the net radiation for bare surfaces $\left(\mathrm{W} \mathrm{m}{ }^{-2}\right)$; $\alpha_{\mathrm{s}}$ is the bare surface albedo (dimensionless); $\varepsilon_{\mathrm{s}}$ is the bare surface emissivity (e.g., 0.95) [Tasumi, 2003]; $T_{\mathrm{s}}$ is the bare surface temperature $(\mathrm{K})$; and $r_{\mathrm{a}, \mathrm{s}}$ is the aerodynamic 
resistance for bare surfaces $\left(\mathrm{s} \mathrm{m}^{-1}\right)$. In M-SEBAL, $r_{\mathrm{a}, \mathrm{s}}$ is computed with Kondo's formulas [Kondo, 1994] (see equation (B1) in Appendix B) and needs to perform atmospheric stability corrections (equations (B2)-(B9)). The first two terms of Taylor's formula of $L_{\mathrm{u}}$ at $T_{\mathrm{a}}$ can be written as

$$
L_{\mathrm{u}}=\varepsilon_{\mathrm{s}} \sigma T_{\mathrm{s}}^{4} \approx \varepsilon_{\mathrm{s}} \sigma T_{\mathrm{a}}^{4}+4 \varepsilon_{\mathrm{s}} \sigma T_{\mathrm{a}}^{3}\left(T_{\mathrm{s}}-T_{\mathrm{a}}\right) .
$$

[34] Substituting equation (16) into equation (14) one obtains

$$
R_{\mathrm{n}, \mathrm{s}}=\left(1-\alpha_{\mathrm{s}}\right) S_{\mathrm{d}}+\varepsilon_{\mathrm{s}} \varepsilon_{\mathrm{a}} \sigma T_{\mathrm{a}}^{4}-\varepsilon_{\mathrm{s}} \sigma T_{\mathrm{a}}^{4}-4 \varepsilon_{\mathrm{s}} \sigma T_{\mathrm{a}}^{3}\left(T_{\mathrm{s}}-T_{\mathrm{a}}\right) .
$$

[35] Let the first three terms on the right side of equation (17) be $R_{\mathrm{n}, \mathrm{s} 0}$, which is the net radiation for the bare surface in which $T_{\mathrm{s}}$ is approximated by $T_{\mathrm{a}}$ in the component of $L_{\mathrm{u}}$. Combining $R_{\mathrm{n}, \mathrm{s} 0}$, equations (15) and (17), and let $G=c R_{\mathrm{n}, \mathrm{s}}$ where $c$ is a calibrated proportionality coefficient, e.g., $0.3 \sim 0.35$ for bare surfaces at the SMACEX site [ Li et al., 2005], one obtains

$$
T_{\mathrm{s}}=\frac{R_{\mathrm{n}, \mathrm{s} 0}-\mathrm{LE}_{\mathrm{s}} /(1-c)}{4 \varepsilon_{\mathrm{s}} \sigma T_{\mathrm{a}}^{3}+\rho \mathrm{c}_{\mathrm{p}} /\left[r_{\mathrm{a}, \mathrm{s}}(1-c)\right]}+T_{\mathrm{a}} .
$$

[36] It is noted that the value of $c$ varies with soil type and moisture conditions as well as time due to the phase shift between $G$ and $R_{\mathrm{n}, \mathrm{s}}$. However, for midmorning to midday, when daytime thermal infrared satellite imagery are typically acquired, the value of $c$ can be assumed constant [Kustas and Anderson, 2009].

[37] For the bare surface with the largest water stress, $\mathrm{LE}_{\mathrm{S}}$ is assumed to be zero. Therefore, the surface temperature for point $\mathrm{A}, T_{\mathrm{s}, \max }$, can be derived as

$$
T_{\mathrm{s}, \max }=\frac{R_{\mathrm{n}, \mathrm{s} 0}}{4 \varepsilon_{\mathrm{s}} \sigma T_{\mathrm{a}}^{3}+\rho \mathrm{c}_{\mathrm{p}} /\left[r_{\mathrm{a}, \mathrm{s}}(1-c)\right]}+T_{\mathrm{a}} .
$$

[38] It is noted that $r_{\mathrm{a}, \mathrm{s}}$ is still a function of $T_{\mathrm{s}, \max }$ involved in $H_{\mathrm{s}}\left(=R_{\mathrm{n}, \mathrm{s}}-G\right)$ in equation (B7). Therefore, equation (19) needs to be solved in an iterative manner. If $T_{\mathrm{s}, \max }$ is not explicitly shown in equation (19) by simplifying $L_{\mathrm{u}}$ with its Taylor series at $T_{\mathrm{a}}$, it can also be solved for in equations (14)-(15) and (B1)-(B9) numerically, which would provide a more precise solution of the nonlinear equation system.

[39] Derivation of $T_{\mathrm{s}, \max }$ requires generally steady atmospheric conditions for a study site (e.g., $T_{\mathrm{a}}$ and $R_{\mathrm{n}, \mathrm{s}}$ ), i.e., there should not be large differences in $T_{\mathrm{a}}$ and $R_{\mathrm{n}, \mathrm{s}}$ between point $\mathrm{A}$ and other surfaces in terms of the deduction of equation (19) from equation (18). Some studies estimated ET at continental scales using triangle models [e.g., Nishida et al., 2003; Sun et al., 2010], which may have exaggerated the applicability of triangle models due to the contradiction of their implicit assumptions. In fact, SEBAL is also conditioned by this requirement. In practical application, $T_{\mathrm{a}}$ and $e_{\mathrm{a}}$ involved in equations (14)-(19) can take areally averaged values of $T_{\mathrm{a}}$ and $e_{\mathrm{a}}$ observations at EC towers or weather stations.
[40] In a similar vein, the temperature for the fully vegetated surface (point D) with the largest water stress, $T_{\mathrm{c}, \max }$, can be derived as

$$
T_{\mathrm{c}, \max }=\frac{R_{\mathrm{n}, \mathrm{c} 0}}{4 \varepsilon_{\mathrm{c}} \sigma T_{\mathrm{a}}^{3}+\rho \mathrm{c}_{\mathrm{p}} / r_{\mathrm{a}, \mathrm{c}}}+T_{\mathrm{a}},
$$

where $R_{\mathrm{n}, \mathrm{c} 0}$ is the radiation for the fully vegetated surface in which $T_{\mathrm{c}}$ is approximated by $T_{\mathrm{a}}$ in the component of $L_{\mathrm{u}}$; $\varepsilon_{\mathrm{c}}$ is the vegetation emissivity $(0.98)$ [Tasumi, 2003]; and $r_{\mathrm{a}, \mathrm{c}}$ is the aerodynamic resistance for the fully vegetated surface (see equations (B10)-(B24)).

[41] Note that the major differences between equations (19) and (20) lie in the aerodynamic resistance $\left(r_{\mathrm{a}, \mathrm{s}}\right.$ and $\left.r_{\mathrm{a}, \mathrm{c}}\right)$ and net radiation $\left(R_{\mathrm{n}, \mathrm{s} 0}\right.$ and $\left.R_{\mathrm{n}, \mathrm{c} 0}\right)$, which characterize the differences in the physiologic and surface properties. Surface albedo for the two surfaces $\left(\alpha_{\mathrm{s}}\right.$ in $R_{\mathrm{n}, \mathrm{s} 0}$ and $\alpha_{\mathrm{c}}$ in $R_{\mathrm{n}, \mathrm{c} 0}$ ) can be obtained from measurements or deduced by extending the upper envelope of the $f_{\mathrm{c}}-\alpha$ space to $f_{\mathrm{c}}=0$ and $f_{\mathrm{c}}=1$, respectively. Compared with formulas for deriving $T_{\mathrm{s}, \max }$ and $T_{\mathrm{c}, \max }$ by Jackson et al. [1981] and Moran et al. [1994], the calculation procedures here do not call for near surface measurements of radiation and vapor pressure deficit specifically for the two extreme surfaces.

\section{Study Site and Materials}

\subsection{Study Site}

[42] The SMACEX campaign was conducted in central Iowa, ranging in latitude between $41.87^{\circ} \mathrm{N}$ and $42.05^{\circ} \mathrm{N}$ and in longitude between $-93.83^{\circ} \mathrm{W}$ and $-93.39^{\circ} \mathrm{W}$ (Figure 3) during the period from 15 June (DOY 166) through 8 July (DOY 189) in 2002. The campaign provided extensive measurements of soil, vegetation, meteorological properties and statesfor a greater understanding of the mechanisms of water and heat exchanges with the atmosphere [Kustas et al., 2005]. This data set provides a unique opportunity to perform rigorous evaluation and comparison of a series of satellite-based models for surface flux estimation. The field campaign was primarily conducted in the Walnut Creek watershed, just south of Ames in central Iowa. Rainfed corn and soybean fields dominate the Walnut Creek watershed. During the course of campaign, crops and vegetation grew rapidly. The surface soil moisture changed from dry to wet after rainfall events in early July.

[43] The mean annual rainfall of this region is $835 \mathrm{~mm}$, which can be classified as a humid climate. Precipitation during the SMACEX campaign occurred a few days prior to 15 June (DOY 166), with a minor rainfall event of $0-5 \mathrm{~mm}$ on 20 June (DOY 171). This was followed by a rain-free period for the Walnut Creek watershed until 4 July (DOY 185). In a typical growing season, the most rapid growth in corn and soybean crops is observed in June and July. Elevation of the SMACEX site ranges from $256 \mathrm{~m}$ to $354 \mathrm{~m}$, with a mean of $302 \mathrm{~m}$. The topography is characterized by low relief and poor surface drainage.

\subsection{Flux Tower Measurements}

[44] A network consisting of 14 meteorological-flux (METFLUX) towers (12 were fully operational during the campaign) was deployed within or in the vicinity of the 


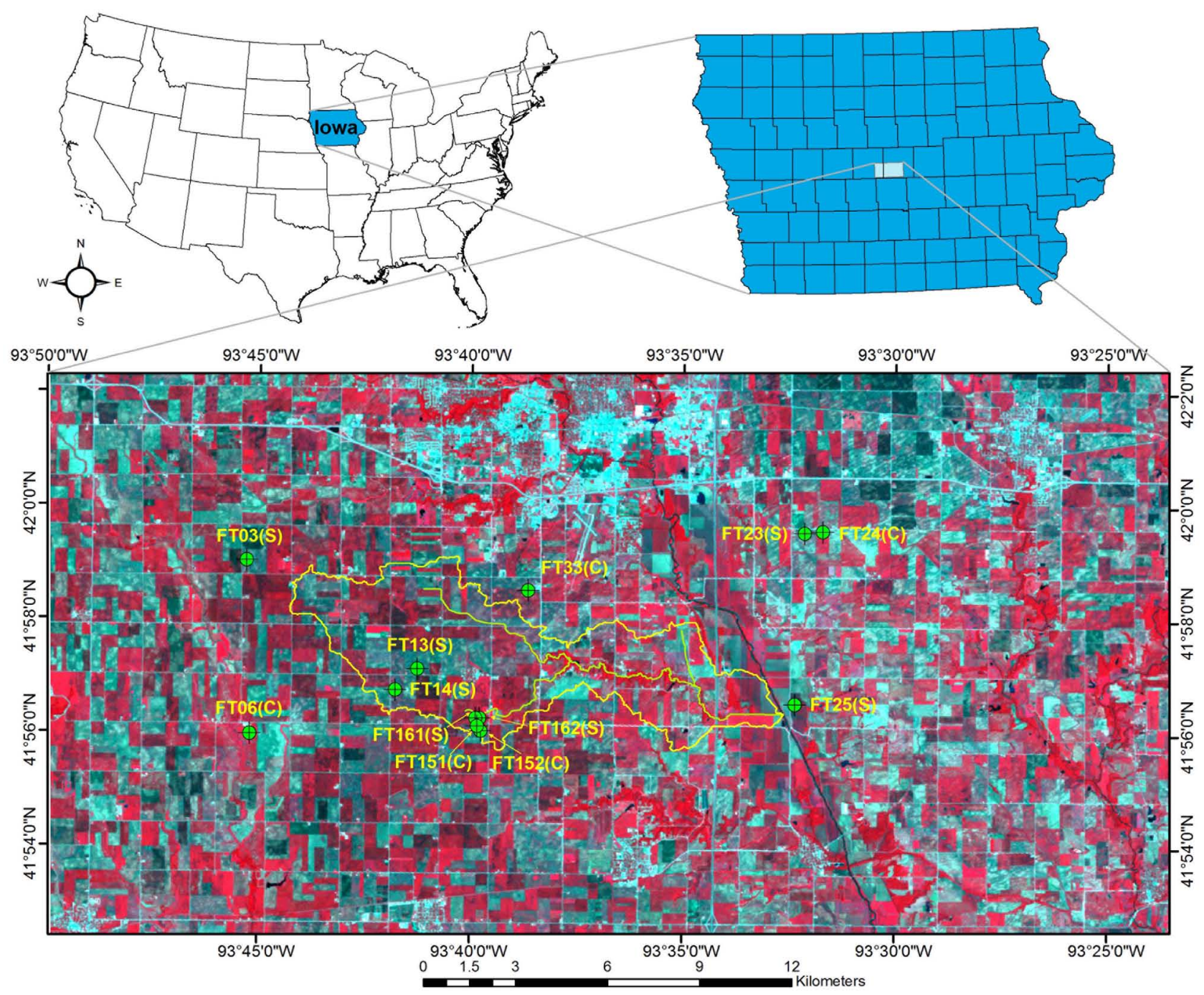

Figure 3. Location and false color composite of Landsat TM imagery acquired on 23 June (DOY 174) 2002, of the SMACEX site in Ames, central Iowa, U.S. The Walnut Creek watershed is delineated in yellow and the main Walnut Creek and its branch are shown in olivine. The meteorological-flux network, comprising 12 flux towers (FT), is shown in numbered green circles nested with cross wires. Crop types of these flux towers are characterized by soybean $(\mathrm{S})$ or corn $(\mathrm{C})$.

Walnut Creek watershed (FT 3, 6, 23, 24, 25, and 33 were outside the watershed), employing EC systems at 12 field sites, in which six sites were corn and six sites were soybean (denoted as $\mathrm{C}$ and $\mathrm{S}$ in Figure 3, respectively). These towers were instrumented with a variety of sensors for measuring turbulent fluxes of latent and sensible heat, as well as radiation components (i.e., incoming and outgoing shortwave and long wave radiation) and soil heat fluxes at 30-min intervals. Additional in situ hydrometeorological observations encompassed 10-min-averaged temperature, relative humidity, wind speed and direction, etc. Observed fluxes for three image acquisition dates were used to evaluate SEBAL and M-SEBAL. Details about these sensors and processing of the measurements can be found in the work of Kustas et al. [2005] and Prueger et al. [2005]. It is noted that DOY 189 showed relatively large LE fluxes and small $H$ fluxes. FT 3, 6, 14, and 24 (Figure 3) even showed negative $H$ measurements, which may have indicated the presence of advection on that day.

\subsection{Closure for Energy Balance}

[45] The eddy covariance systems have been found to underestimate $\mathrm{LE}$ and $H$, i.e., $\Delta E>\mathrm{LE}+H$; therefore, the measured LE and $H$ need to be adjusted for closure for energy balance. Twine et al. [2000] stated that the preferred method of energy balance closure is to maintain the Bowen ratio $(H / \mathrm{LE})$ and partition the measured $\Delta E$, since there was no compelling evidence to discard the measured LE as the residual closure, for which the measured LE is taken to be the residual of measured $R_{\mathrm{n}}, G$, and $H$. They also compared the measured LE after forcing the closure by the Bowen ratio and residual techniques with that from water budget calculations, indicating that the Bowen ratio method showed closer agreement with the water balance results. 


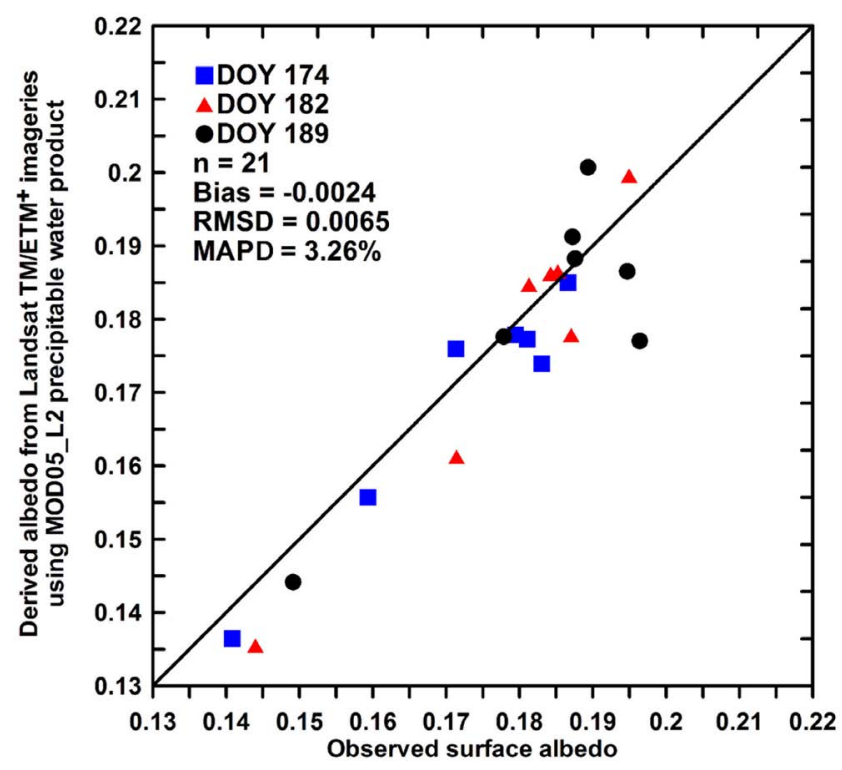

Figure 4. Comparison of $\alpha$ measurements (observed outgoing shortwave radiation and observed incoming shortwave radiation) and $\alpha$ retrievals from Landsat $\mathrm{TM} / \mathrm{ETM}^{+}$ images combined with the MOD05_L2 precipitable water product at the SMACEX site for $3 \mathrm{~d}$ in 2002.

Anderson et al. [2005] found that the observed LE, after forcing the closure by the Bowen ratio method, agreed well with aircraft counterparts for the SMACEX site. French et al. [2005b] performed the Bowen ratio-based closure in an evaluation of TSEB and SEBAL at the SMACEX site. As such, a closure of the measured LE and $H$ fluxes by the Bowen ratio technique was performed here.

\subsection{Remote Sensing Sources and Ancillary Data Sets}

[46] The period of SMACEX permitted three scenes of cloud-free Landsat TM/ETM ${ }^{+}$imageries, i.e., Landsat TM (path/row: 26/31) acquired at 10:20 A.M. (local time) on DOY 174 spanning $f_{\mathrm{c}}$ from $50 \%$ to $75 \%$, Landsat $\mathrm{ETM}^{+}$ $(26 / 31)$ acquired at 10:42 A.M. on DOY 182 from $75 \%$ to $90 \%$, and Landsat $\mathrm{ETM}^{+}(27 / 31)$ acquired at 10:45 A.M. on DOY 189 from $85 \%$ to essentially full cover.

[47] A land cover map for the SMACEX site (available at http://nsidc.org/data/docs/daac/nsidc0276_smex02_landclass. gd.html) was obtained for use in facilitating the extreme pixel selection required by SEBAL. Digital elevation models (DEMs) were obtained from the National Elevation Data set (NED) produced and distributed by the U.S. Geological Survey (available at http://seamless.usgs.gov/index. php) for use in simulating $R_{\mathrm{n}}$ by accounting for the influence of terrain factors on direct solar radiation [Long et al., 2010], with a spatial resolution of 1 arc-s $(\sim 30 \mathrm{~m})$.

\section{Derivation of Critical Variables}

\section{1. $\alpha, \alpha_{s}$, and $\alpha_{c}$}

[48] Derivation of albedo from the visible and near-infrared bands of Landsat imagery is essential to determining net shortwave radiation for both SEBAL and M-SEBAL. Here the algorithm developed by Tasumi et al. [2008] was employed. In this algorithm, the precipitable water content in the atmosphere $(w)$ is needed, which can be estimated using an empirical formula relating $w$ to $e_{\mathrm{a}}$ and atmospheric pressure $(P)$ [Garrison and Adler, 1990]. For reserving the spatial characteristics of $w$ across the study site, we utilized the MODIS-based $w$ data product (MOD05_L2) at the Landsat overpass as an input to derive albedo. Albedo measurements were obtained using the measured outgoing

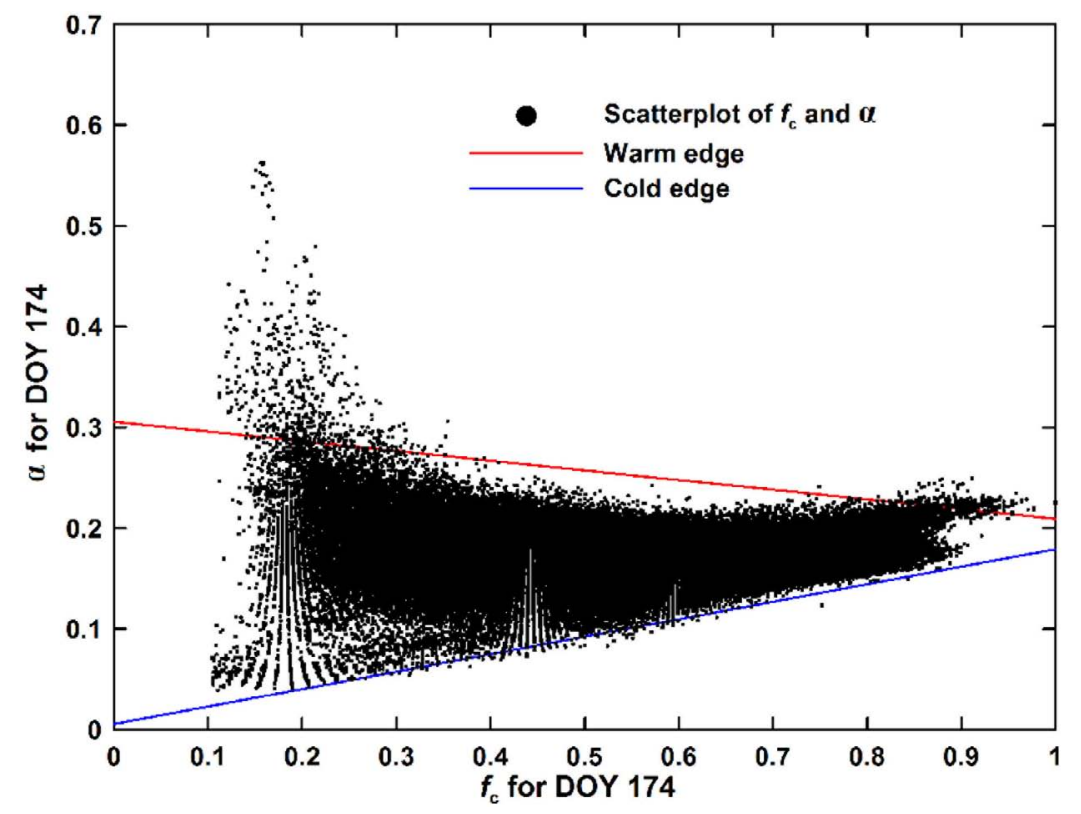

Figure 5. Scatterplot of $f_{\mathrm{c}}$ and $\alpha$ at the SMACEX site on DOY 174 in 2002, showing the warm (upper) and cold (lower) envelopes of the space. The intercept of the upper envelope is taken as the $\alpha$ of the bare surface with the largest water stress. The upper envelope intersecting with $f_{\mathrm{c}}=1$ is taken as the $\alpha$ of the fully vegetated surface with the largest water stress. 


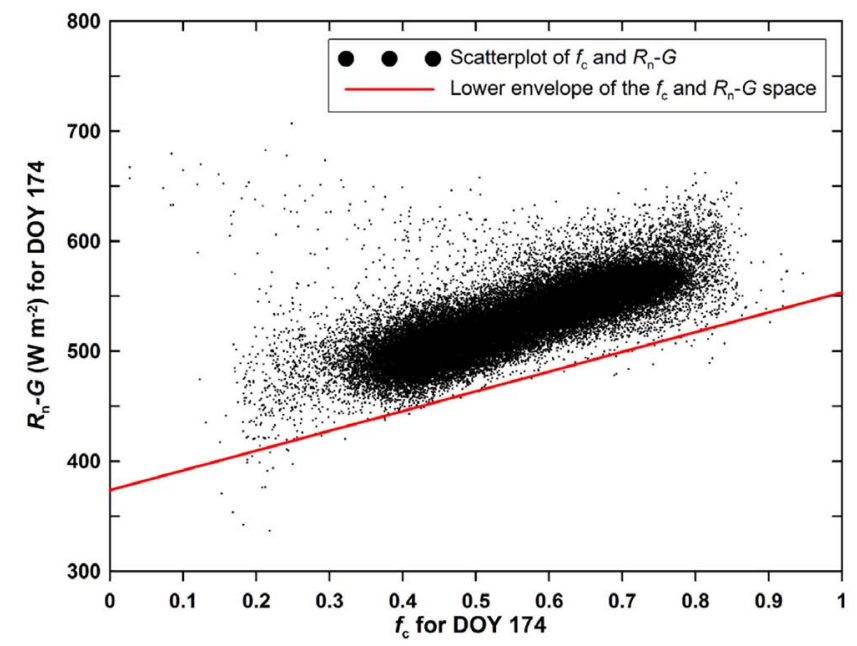

Figure 6. Scatterplot of $f_{\mathrm{c}}$ and $\Delta E$ at the SMACEX site on DOY 174 in 2002. The warm edge (lower envelope) of the space represents $\Delta E$ for the theoretical warm edge of the $f_{\mathrm{c}}$ and $T_{\text {rad }}$ space.

over the incoming shortwave radiation at seven EC sites encompassing observations of both the incoming and outgoing shortwave radiation. Figure 4 compares the derived albedo with the observed one. Results indicate that the albedo algorithm in combination with the input of MODISbased precipitable water content seems to be capable of retrieving albedo with relatively high accuracy, implying a root-mean-square difference (RMSD) of 0.0065 and mean absolute percentage difference (MAPD) of $3.26 \%$ for three test dates. RMSD and MAPD were calculated using equations (A3) and (A4).

[49] In determination of the vertices of the trapezoidal framework in M-SEBAL, albedo for points A and D are required to trigger radiation budget and energy balance calculations. If there are no measurements of $\alpha_{\mathrm{s}}$ and $\alpha_{\mathrm{c}}$, we suggest that the $f_{\mathrm{c}}-\alpha$ space could be used to deduce albedo for the two extreme surfaces. Figure 5 gives an example of the $f_{\mathrm{c}}-\alpha$ space on DOY 174. For the same $f_{\mathrm{c}}$, large albedo could indicate relatively high $T_{\mathrm{rad}}$ and low soil moisture, and vice versa. The contextual relationship between $\alpha$ and $T_{\text {rad }}$ underpins another type of remotely sensed ET model [Roerink et al., 2000]. It is, therefore, plausible to deduce $\alpha_{\mathrm{s}}$ and $\alpha_{\mathrm{c}}$ from the $f_{\mathrm{c}}-\alpha$ space, in which the upper envelope is extended to intercept with $f_{\mathrm{c}}=0$ and $f_{\mathrm{c}}=1$ to deduce albedo for points $\mathrm{A}$ and $\mathrm{D}$, respectively. The upper envelope is determined by the following steps: the full range of $f_{\mathrm{c}}$ can be divided into $n$ classes (e.g., $n=100$ ); data pairs of the largest albedo and its $f_{\mathrm{c}}$ are selected; outliers for the selected data pairs will be discarded by setting thresholds (e.g., outside the range $[\mu-\sigma, \mu+\sigma]$, where $\mu$ and $\sigma$ are the mean and standard deviation, respectively); and the refined extreme pairs are used to perform a linear regression. The intercept of the upper edge is taken as $\alpha_{\mathrm{s}}$ and the value of the upper edge at $f_{\mathrm{c}}=1$ is taken as $\alpha_{\mathrm{c}}$.

\section{2. $\Delta E_{i \text {,hot }}$}

[50] As discussed in section 2.5, the energy state of the theoretical warm edge for a full range of $f_{\mathrm{c}}$ in M-SEBAL needs to be deduced. We take advantage of the $f_{\mathrm{c}}-\Delta E$ space to deduce $\Delta E$ for the warm edge, deriving the lower envelope of the space. Figure 6 provides an example of the $f_{\mathrm{c}}-\Delta E$ space at the SMACEX site for DOY 174. It is apparent that with increasing $f_{\mathrm{c}}, \Delta E$ also increases. This is likely because decreasing $T_{\mathrm{rad}}, \alpha$, and $G$, all contribute to increasing $R_{\mathrm{n}}$ and decreasing $G$. Determination of the lower envelope of the $f_{\mathrm{c}}-\Delta E$ space is similar to the steps illustrated in section 4.1 for determining the upper edge of the $f_{\mathrm{c}}-\alpha$ space.

\section{3. $T_{\mathrm{rad}}$}

[51] $T_{\text {rad }}$ derived from thermal infrared band(s) of satellite imagery plays a prominent role in all satellite-based ET models, as it is essential in determining turbulent fluxes

Table 1. Statistics on Discrepancies Between Simulated Energy Balance Components From M-SEBAL and Eddy Covariance Energy and Heat Fluxes at the SMACEX Site for Three Test Dates in 2002

\begin{tabular}{|c|c|c|c|c|c|c|c|}
\hline \multicolumn{2}{|c|}{ Flux and Date } & \multirow{2}{*}{$\begin{array}{c}\begin{array}{c}\text { Observation } \\
\text { Number }\end{array} \\
12\end{array}$} & \multirow{2}{*}{$\begin{array}{c}\begin{array}{c}\text { Observed } \\
\text { Average }\left(\mathrm{W} \mathrm{m}^{-2}\right)\end{array} \\
572.4\end{array}$} & \multirow{2}{*}{$\begin{array}{c}\begin{array}{c}\text { Simulated } \\
\text { Average }\left(\mathrm{W} \mathrm{m}^{-2}\right)\end{array} \\
592.4\end{array}$} & \multirow{2}{*}{$\frac{\operatorname{Bias}\left(\mathrm{W} \mathrm{m}^{-2}\right)}{20.0}$} & \multirow{2}{*}{$\frac{\operatorname{RMSD}\left(\mathrm{W} \mathrm{m}^{-2}\right)}{29.7}$} & \multirow{2}{*}{$\begin{array}{c}\begin{array}{c}\text { MAPD } \\
\text { (Percent) }\end{array} \\
4.3\end{array}$} \\
\hline$R_{\mathrm{n}}$ & DOY174 & & & & & & \\
\hline & DOY182 & 12 & 586.5 & 604.6 & 18.1 & 27.1 & 3.6 \\
\hline & DOY189 & 11 & 606.4 & 615.2 & 8.7 & 26.7 & 3.3 \\
\hline & Overall & 35 & 587.9 & 603.7 & 15.8 & 27.9 & 3.8 \\
\hline \multirow[t]{4}{*}{$G$} & DOY174 & 12 & 104.1 & 90.4 & -13.6 & 31.0 & 25.5 \\
\hline & DOY182 & 12 & 74.1 & 85.0 & 10.9 & 21.0 & 36.4 \\
\hline & DOY189 & 11 & 82.7 & 73.9 & -8.8 & 21.7 & 23.7 \\
\hline & Overall & 35 & 87.1 & 83.4 & -3.7 & 25.1 & 28.7 \\
\hline \multirow[t]{4}{*}{ LE } & DOY174 & 9 & 346.6 & 350.2 & 3.7 & 39.8 & 10.3 \\
\hline & DOY182 & 10 & 399.8 & 380.9 & -19.0 & 43.3 & 9.8 \\
\hline & DOY189 & 11 & 501.3 & 503.6 & 2.3 & 40.1 & 6.8 \\
\hline & Overall & 30 & 421.0 & 416.7 & -4.4 & 41.1 & 8.9 \\
\hline \multirow[t]{4}{*}{$H$} & DOY174 & 9 & 123.4 & 152.5 & 29.1 & 37.6 & 24.8 \\
\hline & DOY182 & 10 & 124.6 & 145.9 & 21.3 & 35.5 & 30.6 \\
\hline & DOY189 & 11 & 22.4 & 37.6 & 15.2 & 19.2 & 144.4 \\
\hline & Overall & 30 & 86.8 & 108.2 & 21.4 & 31.3 & 70.6 \\
\hline \multirow[t]{4}{*}{$\mathrm{EF}$} & DOY174 & 9 & 0.73 & 0.69 & -0.04 & 0.07 & 7.4 \\
\hline & DOY182 & 10 & 0.76 & 0.72 & -0.04 & 0.07 & 8.5 \\
\hline & DOY189 & 11 & 0.96 & 0.93 & -0.03 & 0.04 & 3.4 \\
\hline & Overall & 30 & 0.82 & 0.79 & -0.04 & 0.06 & 6.3 \\
\hline
\end{tabular}

${ }^{a}$ The observed fluxes were corrected by the Bowen ratio (BR) technique. 

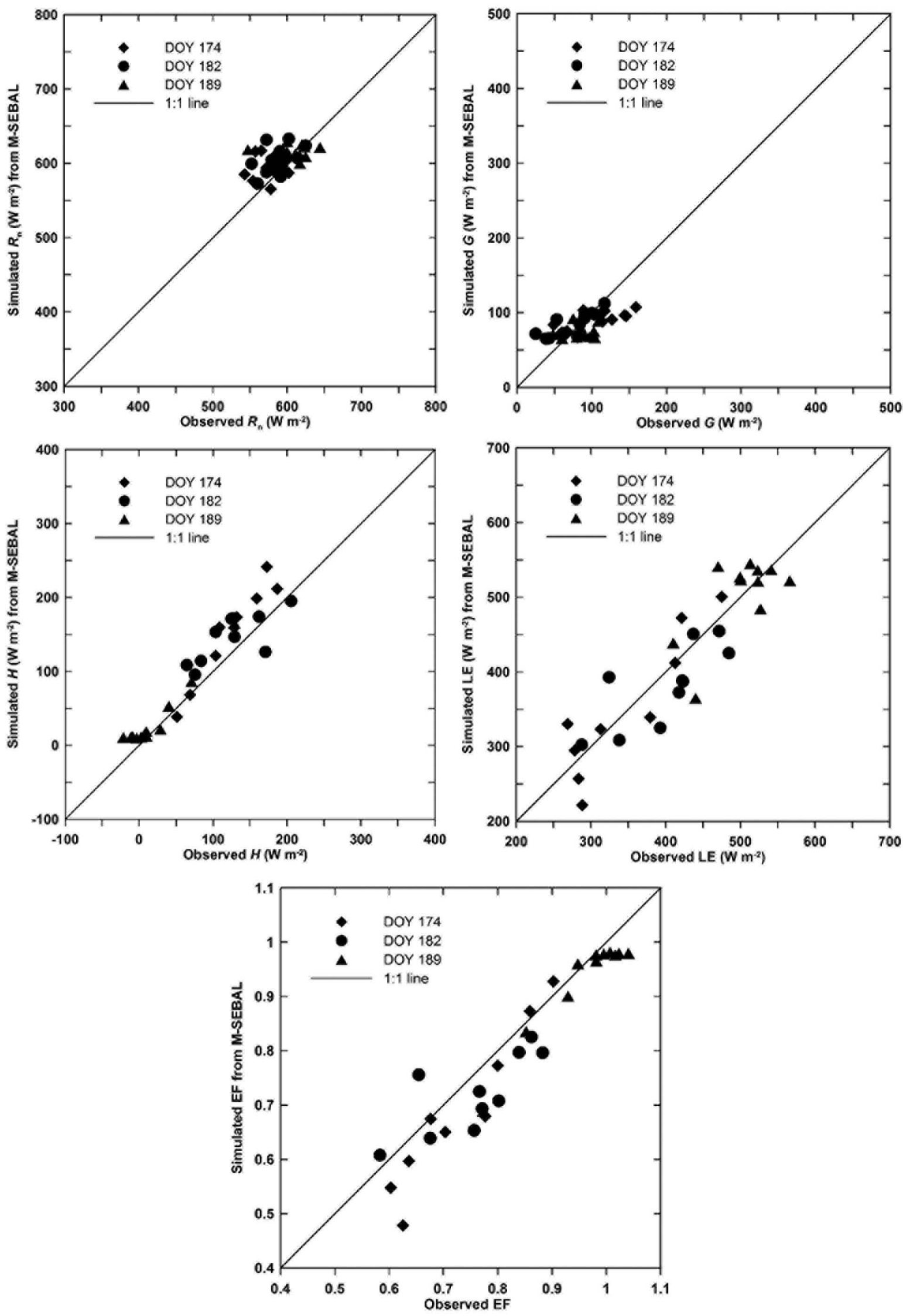

Figure 7. Comparison of $R_{\mathrm{n}}, G, H, \mathrm{LE}\left(\mathrm{W} \mathrm{m}^{-2}\right)$, and $\mathrm{EF}$ estimates from M-SEBAL with corresponding EC tower-based measurements at the SMACEX site on DOY 174, 182, and 189 in 2002. 
between the surface and the lower atmosphere. Landsat imagery can only provide one thermal infrared band, resulting in the difficulty of deriving $T_{\text {rad }}$ compared with other satellite platforms (e.g., Terra/Aqua-MODIS) having multiple thermal infrared bands. In this case, radio-sounding data and/or measurements (e.g., $T_{\mathrm{a}}$ and $e_{\mathrm{a}}$ ) for the atmospheric profile are required to perform atmospheric and emissivity corrections to convert the at-sensor brightness temperature to $T_{\mathrm{rad}}$. Li et al. [2004] performed atmospheric corrections for the thermal infrared bands of Landsat imageries for the SMACEX site using MODTRAN [Berk et al., 1998], providing simulated narrow band atmospheric transmittance $(10.4-12.5 \mu \mathrm{m})$, path radiance $(10.4-12.5 \mu \mathrm{m})$, and narrow band downward thermal radiation from a clear sky. Here we derived $T_{\text {rad }}$ for the three scenes of Landsat TM/ETM ${ }^{+}$ imageries using those parameters derived by $L i$ et al. [2004]. Surface emissivity for the thermal infrared band $(10.4 \sim 12.5 \mu \mathrm{m})$ was estimated by the formula proposed by Sobrino et al. [2001] (see equation (A2)).

\section{Results and Discussion}

\subsection{Results From M-SEBAL}

[52] Energy balance components simulated by M-SEBAL were compared with EC tower flux measurements. The prevailing wind direction during three Landsat imagery acquisition days was from the south-southwest. Chavez et al. [2005] showed that most footprints were 100-140 m long, with most of the weight concentrated in the first $60 \mathrm{~m}$ upwind from the flux stations. The simulated fluxes were averaged over the estimated upwind source-area/footprint $(120 \mathrm{~m} \times 180 \mathrm{~m}$, $2 \times 3$ thermal band pixels) for each flux tower [Choi et al., 2009; Gonzalez-Dugo et al., 2009]. Results (Table 1 and Figure 7) indicate that M-SEBAL seems to be capable of reproducing surface fluxes with reasonable accuracy at the SMACEX site for three test days in 2002. The most interesting output of M-SEBAL, LE, shows discrepancies between the retrievals and the ground-based measurements in terms of an overall bias (calculated using equation (A5)) of $-4.4 \mathrm{~W}$ $\mathrm{m}^{-2}, \mathrm{RMSD}$ of $41.1 \mathrm{~W} \mathrm{~m}^{-2}$, and MAPD of $8.9 \%$.

[53] These discrepancies are generally within the intrinsic uncertainty in flux tower-based measurements. The retrieval accuracy of M-SEBAL seems to be comparable to TSEB models (both series and parallel configurations) showing an RMSD on an order of $\sim 40 \mathrm{~W} \mathrm{~m}^{-2}$, which has been applied to the SMACEX site in a series of evaluation and comparison studies [e.g., Choi et al., 2009; French et al., 2005a; Gonzalez-Dugo et al., 2009; Li et al., 2005]. SEBS reproduced LE over the SMACEX site on DOY 182 with a bias of $-6 \mathrm{~W} \mathrm{~m}^{-2}$ for the Landsat $\mathrm{ETM}^{+}$imagery [McCabe and Wood, 2006]. Furthermore, $R_{\mathrm{n}}$ and $G$ can also be reproduced reasonably well by M-SEBAL, showing RMSD varying between 20 and $30 \mathrm{~W} \mathrm{~m}^{-2}$.

[54] To isolate uncertainties in $R_{\mathrm{n}}, G$, and $H$ retrievals for LE, we computed EF for sites having all of the measurements of $R_{\mathrm{n}}, G, H$, and LE. The EF retrievals from M-SEBAL show closer agreement with ground-based measurements than the LE retrievals (Table 1 and Figure 7), suggesting a bias of -0.04 , RMSD of 0.06 , and MAPD of $6.3 \%$. These discrepancies are essentially smaller than those of the triangle models which normally reproduce EF
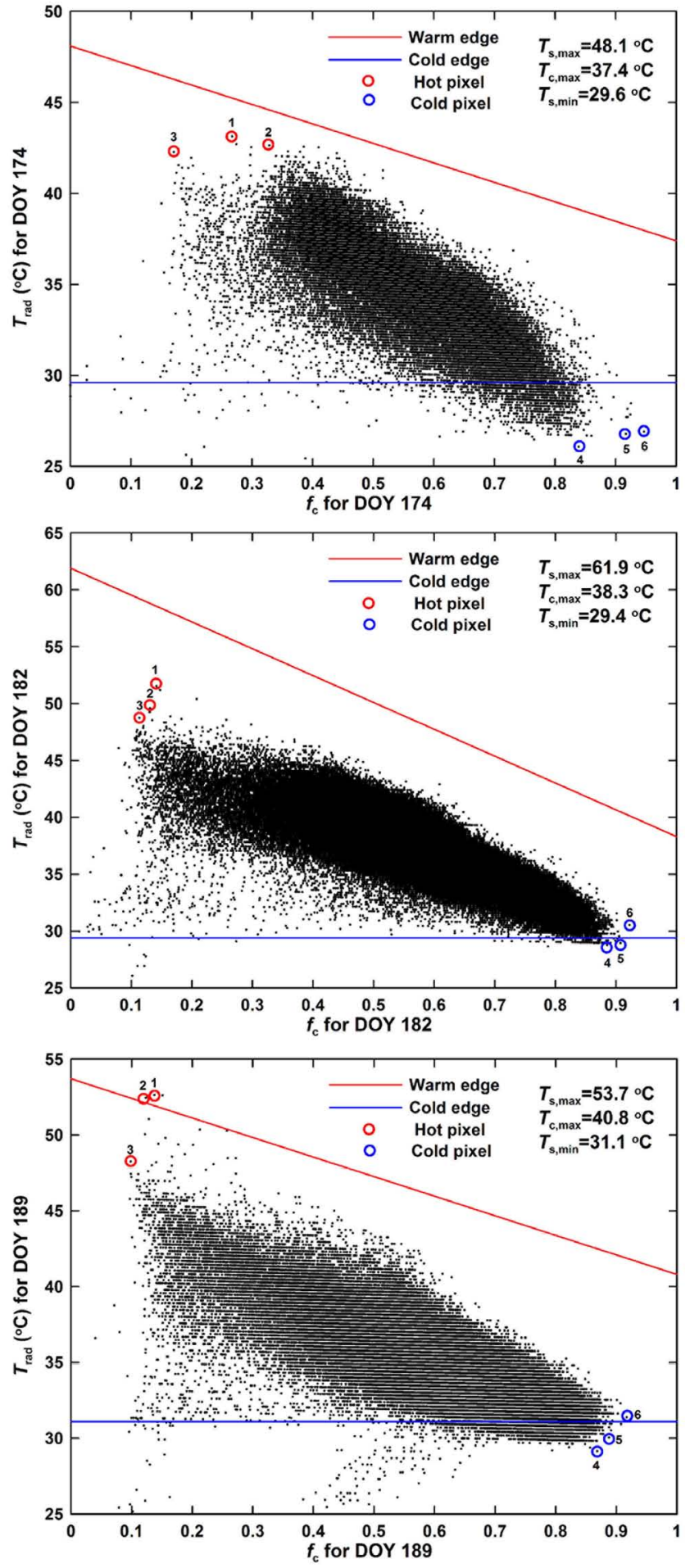

Figure 8. Scatterplots of $f_{\mathrm{c}}$ and $T_{\mathrm{rad}}$ for the SMACEX site for DOY 174,182 , and 189 in 2002. Numbered red circles represent hot extreme candidates, and numbered blue circles represent cold extreme candidates. Red (warm) and blue (cold) lines represent the limiting edges of the trapezoidal framework in M-SEBAL, showing temperatures of vertices $\left(T_{\mathrm{s}, \max }\right.$ and $\left.T_{\mathrm{c}, \max }\right)$ and the cold edge $\left(T_{\mathrm{a}}\right)$. 
Table 2. Extreme Pixels With Characteristic Variables as Inputs of SEBAL at SMACEX Site for DOY 174, 182, and 189 in $2002^{\mathrm{a}}$

\begin{tabular}{|c|c|c|c|c|c|c|c|c|c|c|c|c|c|c|c|}
\hline \multirow{2}{*}{$\begin{array}{l}\text { Case (Hot Pixel, } \\
\text { Cold Pixel) }\end{array}$} & \multicolumn{3}{|c|}{$T_{\mathrm{s}, \text { hot }}\left({ }^{\circ} \mathrm{C}\right)$} & \multicolumn{3}{|c|}{$\left(R_{\mathrm{n}}-G\right)_{\text {hot }}\left(\mathrm{W} \mathrm{m}^{-2}\right)$} & \multicolumn{3}{|c|}{$f_{\mathrm{c}, \text { hot }}(-)$} & \multicolumn{3}{|c|}{$T_{\mathrm{s}, \text { cold }}\left({ }^{\circ} \mathrm{C}\right)$} & \multicolumn{3}{|c|}{$f_{\mathrm{c}, \text { cold }}(-)$} \\
\hline & 174 & 182 & 189 & 174 & 182 & 189 & 174 & 182 & 189 & 174 & 182 & 189 & 174 & 182 & 189 \\
\hline $1(1,4)$ & 43.1 & 51.5 & 52.6 & 467.0 & 442.5 & 399.6 & 0.27 & 0.14 & 0.14 & 26.1 & 28.8 & 29.1 & 0.84 & 0.87 & 0.87 \\
\hline $2(2,4)$ & 42.6 & 49.6 & 52.5 & 478.3 & 440.9 & 401.1 & 0.17 & 0.13 & 0.12 & 26.1 & 28.8 & 29.1 & 0.84 & 0.87 & 0.87 \\
\hline $3(3,4)$ & 42.3 & 48.7 & 48.3 & 481.7 & 442.5 & 338.8 & 0.33 & 0.13 & 0.10 & 26.1 & 28.8 & 29.1 & 0.84 & 0.87 & 0.87 \\
\hline $4(1,5)$ & 43.1 & 51.5 & 52.6 & 467.0 & 442.5 & 399.6 & 0.27 & 0.14 & 0.14 & 26.8 & 29.0 & 30.1 & 0.92 & 0.90 & 0.89 \\
\hline $5(2,5)$ & 42.6 & 49.6 & 52.5 & 478.3 & 440.9 & 401.1 & 0.17 & 0.13 & 0.12 & 26.8 & 29.0 & 30.1 & 0.92 & 0.90 & 0.89 \\
\hline $6(3,5)$ & 42.3 & 48.7 & 48.3 & 481.7 & 442.5 & 338.8 & 0.33 & 0.13 & 0.10 & 26.8 & 29.0 & 30.1 & 0.92 & 0.90 & 0.89 \\
\hline $7(1,6)$ & 43.1 & 51.5 & 52.6 & 467.0 & 442.5 & 399.6 & 0.27 & 0.14 & 0.14 & 26.9 & 30.5 & 31.4 & 0.94 & 0.92 & 0.92 \\
\hline $8(2,6)$ & 42.6 & 49.6 & 52.5 & 478.3 & 440.9 & 401.1 & 0.17 & 0.13 & 0.12 & 26.9 & 30.5 & 31.4 & 0.94 & 0.92 & 0.92 \\
\hline $9(3,6)$ & 42.3 & 48.7 & 48.3 & 481.7 & 442.5 & 338.8 & 0.33 & 0.13 & 0.10 & 26.9 & 30.5 & 31.4 & 0.94 & 0.92 & 0.92 \\
\hline
\end{tabular}

${ }^{\text {a }}$ Cases 1-9 represent all combinations of three hot pixels (numbered 1-3) and three cold pixels (numbered 4-6) selected from the satellite images.

with an RMSD >0.1 [e.g., Nishida et al., 2003; Stisen et al., 2008].

[55] It is noted that the $H$ estimates from M-SEBAL suggest a relatively larger discrepancy compared with the estimates of other energy balance components, even showing an MAPD up to $144.4 \%$ on DOY 189 . This could a consequence of relatively small magnitudes of the $H$ observations and the presence of advection on that day, which led to the negative $H$ values at FT $3\left(-18 \mathrm{~W} \mathrm{~m}^{-2}\right), 6\left(-3 \mathrm{~W} \mathrm{~m}^{-2}\right)$, $14\left(-10 \mathrm{~W} \mathrm{~m}^{-2}\right)$, and $24\left(-7 \mathrm{~W} \mathrm{~m}^{-2}\right)$. Since M-SEBAL does not involve a mechanism to simulate advective energy, the $H$ estimates for surfaces influenced by advection showed a relatively large uncertainty. However, surfaces/pixels suffering from advection $\left(T_{\mathrm{rad}}<T_{\mathrm{a}}\right)$ could be detected due to the use of observed $T_{\mathrm{a}}$ as the lower boundary of the trapezoidal framework in the M-SEBAL algorithm. The lack of a complete mechanism to model advection seems to marginally influence the most interesting component, the LE estimates, showing a bias of $2.3 \mathrm{~W} \mathrm{~m}^{-2}$, RMSD of $40.1 \mathrm{~W} \mathrm{~m}^{-2}$, and MAPD of $6.8 \%$ on DOY 189 due primarily to the relatively small contribution of $H$ to the energy balance on that day.

[56] Note that $H$ was overestimated by M-SEBAL to a certain degree for each test day, showing an overall bias of $21.4 \mathrm{~W} \mathrm{~m}^{-2}$. This may be a result of the horizontal cold edge formulated in the trapezoidal framework. In fact, the theoretical cold edge would be slanting and essentially above the horizontal one under low $f_{\mathrm{c}}$ conditions (i.e., side $\mathrm{B}^{\prime} \mathrm{C}$ in Figure 1). The downward displaced horizontal cold edge of trapezoid $\mathrm{ABCD}$ would lead to decreasing cold extremes, resulting in an increase in the $H$ estimates and a decrease in the LE estimates. However, substitution of the horizontal cold edge for the slanting one is motivated primarily by circumventing the specification of temperatures of the bare surface without water stress and fully vegetated surface without water stress (points B and C in Figure 1). This simplification could not significantly compromise the retrieval accuracy of LE during the growing season of crops. Most importantly, it can greatly reduce uncertainty and subjectivity involved in SEBAL/METRIC to manually identify the cold pixel; the selection procedure is often influenced by cloud contamination and outliers of $T_{\mathrm{rad}}$ retrievals.

\subsection{Implementation of SEBAL}

[57] Figure 8 shows the $f_{\mathrm{c}}-T_{\text {rad }}$ space at the SMACEX site for three test days derived from the Landsat $\mathrm{TM} / \mathrm{ETM}^{+}$ images, which can facilitate the selection of extremes. Meanwhile, coordinates of these selected extremes were extracted to identify their land cover types from the colorinfrared composite image and land cover information. It is plausible that there are several options to locate hot and cold extremes with differing characteristic variables (i.e., $T_{\text {rad,hot, }}, T_{\text {rad,cold }}$, and $\left.\Delta E_{\text {hot }}\right)$.

[58] Three hot extremes with relatively high $T_{\text {rad }}$ and low $f_{\mathrm{c}}$ values likely correspond to late plantings of soybean crops. Three cold extremes with relatively low $T_{\text {rad }}$ and high $f_{\mathrm{c}}$ values corresponding to full canopy covers for each test day were located (Figure 8 and Table 2). It is noted that the identified hot extremes were not completely bare surfaces, showing $f_{\mathrm{c}}$ values ranging between 0.17 and 0.33 , $\sim 0.14$, and $0.10 \sim 0.12$ for the $3 \mathrm{~d}$, respectively. For a rainfed area, particularly during the period of rapid growth

Table 3. Statistics of Discrepancies Between the $H$ and LE Retrievals From SEBAL and Tower-Based Measurements at SMACEX Site for DOY 174, 182, and 189 in 2002 for Nine Cases $^{\mathrm{a}}$

\begin{tabular}{|c|c|c|c|c|c|c|c|c|c|c|c|c|c|c|c|c|c|c|}
\hline \multirow{2}{*}{$\begin{array}{c}\text { Case } \\
\text { (Hot, Cold) } \\
\text { All days }\end{array}$} & \multicolumn{3}{|c|}{$H: \operatorname{RMSD}\left(\mathrm{W} \mathrm{m}^{-2}\right)$} & \multicolumn{3}{|c|}{$H:$ MAPD (Percent) } & \multicolumn{3}{|c|}{$H: \operatorname{Bias}\left(\mathrm{W} \mathrm{m}^{-2}\right)$} & \multicolumn{3}{|c|}{$\begin{array}{l}\text { LE: RMSD } \\
\left(\mathrm{W} \mathrm{m}^{-2}\right)\end{array}$} & \multicolumn{3}{|c|}{$\begin{array}{c}\text { LE: MAPD } \\
\text { (Percent) }\end{array}$} & \multicolumn{3}{|c|}{$\mathrm{LE}: \operatorname{Bias}\left(\mathrm{W} \mathrm{m}^{-2}\right)$} \\
\hline & 174 & 182 & 189 & 174 & 182 & 189 & 174 & 182 & 189 & 174 & 182 & 189 & 174 & 182 & 189 & 174 & 182 & 189 \\
\hline $1(1,4)$ & 90.2 & 37.7 & 38.8 & 77.8 & 22.1 & 531.1 & 87.5 & -11.2 & 33.9 & 64.4 & 46.6 & 40.5 & 16.6 & 10.2 & 6.6 & -54.8 & 13.5 & -16.3 \\
\hline $2(2,4)$ & 102.2 & 37.4 & 39.1 & 87.7 & 21.0 & 535.4 & 99.3 & -1.0 & 34.3 & 75.5 & 46.2 & 40.8 & 20.3 & 10.0 & 6.6 & -66.6 & 3.3 & -16.8 \\
\hline $3(3,4)$ & 108.3 & 38.7 & 41.2 & 92.6 & 21.6 & 561.8 & 105.2 & 5.2 & 37.0 & 81.2 & 47.3 & 42.3 & 22.2 & 9.8 & 6.9 & -72.5 & -2.9 & -19.4 \\
\hline $4(1,5)$ & 80.4 & 38.6 & 27.5 & 66.7 & 22.9 & 376.6 & 77.0 & -14.0 & 20.1 & 56.5 & 47.6 & 37.0 & 13.8 & 10.4 & 6.6 & -44.2 & 16.3 & -2.5 \\
\hline $5(2,5)$ & 92.2 & 37.7 & 27.6 & 76.2 & 21.6 & 379.5 & 88.5 & -3.9 & 20.4 & 67.0 & 46.8 & 37.1 & 17.2 & 10 & 6.6 & -5 & 6.2 & -2.8 \\
\hline $6(3,5)$ & 98.2 & 38.6 & 29.1 & 81.0 & 21.7 & 401.8 & 94.2 & 2.2 & 22.9 & 72.5 & 47.4 & 37.9 & 19.1 & 10.0 & 6.7 & -61.5 & 0.1 & -5.3 \\
\hline $7(1,6)$ & 79.0 & 51.8 & 19.0 & 65.0 & 39.8 & 199.3 & 75.4 & -36.3 & 0.4 & 55.4 & 60.4 & 40.6 & 13.5 & 13.3 & 7.2 & -42.7 & 38.6 & 17.2 \\
\hline $8(2,6)$ & 90.7 & 47.9 & 19.0 & 74.5 & 35.9 & & & -27.7 & 0.6 & 65.8 & 57.1 & 40.6 & 16.8 & 12.4 & 7.2 & -54.1 & 30.0 & 17.0 \\
\hline $9(3,6)$ & 96.7 & 46.4 & 18.4 & 79.2 & 34.4 & 208.8 & 92.6 & -22.4 & 2.3 & 71.2 & 55.9 & 40.6 & 18.6 & 12.2 & 7.3 & -59.8 & 24.7 & 15.3 \\
\hline
\end{tabular}

${ }^{\mathrm{a}}$ Cases (numbered 1-9) representing different combinations of extreme hot pixels (numbered 1-3) and cold pixels (numbered 4-6, referring to Figure 8). 

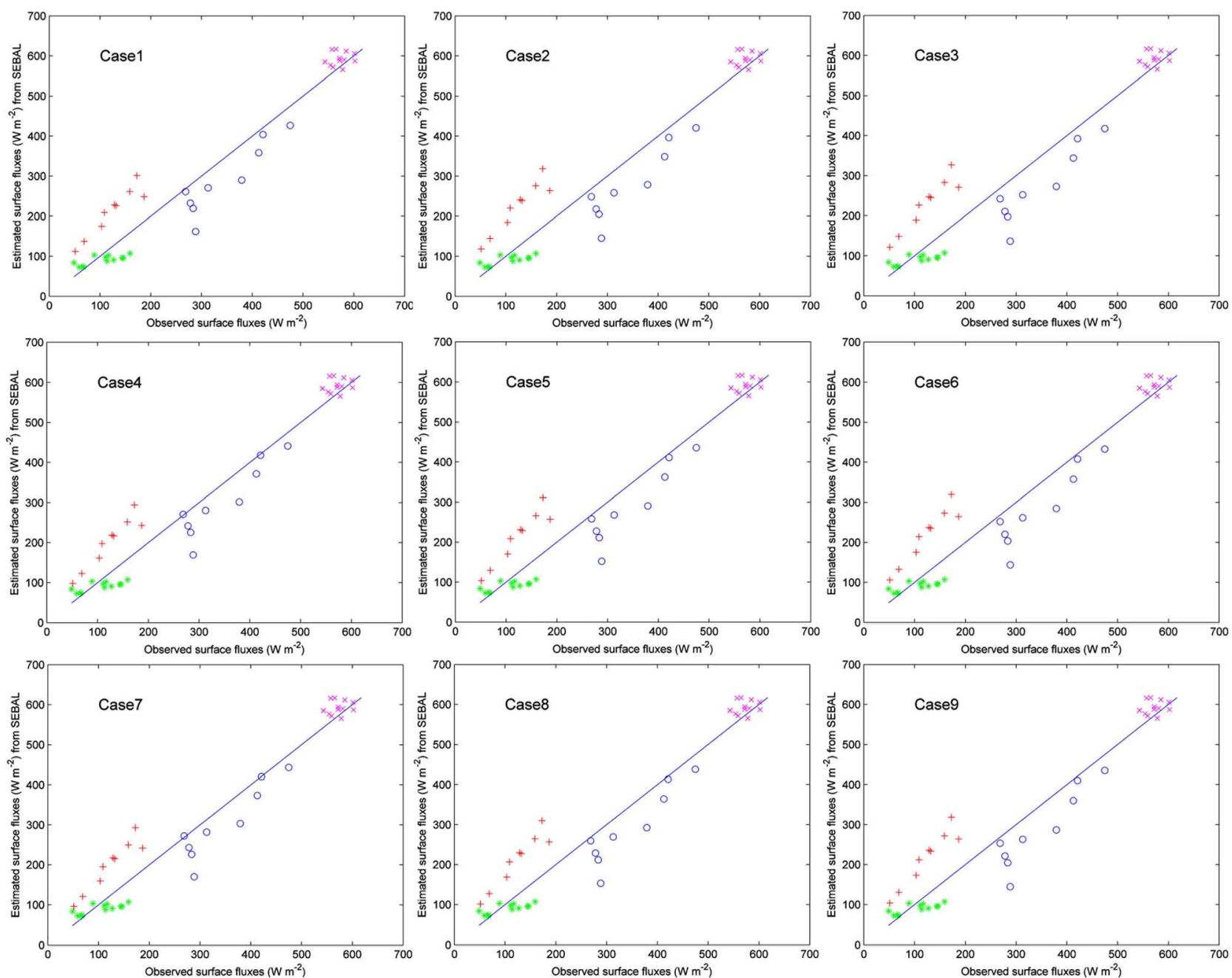

Figure 9. Estimates of $R_{\mathrm{n}}$ (magenta crosses), $G$ (green asterisks), $H$ (red crosses), and LE (blue circles) from SEBAL for nine cases of combinations of selected extremes (see Table 3 ) at the SMACEX site on DOY 174 in 2002.

in crops, a pure bare surface without ET seems to be nonexistent, making the selection of the hot extreme, which completely satisfies the hypothesis, from the satellite image impossible. On the other hand, temperatures of the identified cold extremes on DOY 174 and DOY 189 are generally lower than the cold edge of the trapezoidal framework; there are a cluster of data points whose $T_{\text {rad }}$ values are generally lower than $T_{\mathrm{a}}$ for DOY 174 and DOY 189 (Figure 8). This may result from the uncertainties in $T_{\text {rad }}$ retrievals/ cloud effects or advection (DOY 189). The large dependence of SEBAL on the extreme $T_{\text {rad }}$ values, particularly on $T_{\text {rad,cold, }}$ makes SEBAL considerably susceptible to uncertainties in the $T_{\text {rad }}$ retrievals and reduces its robustness.

[59] There are in total nine combinations of a hot and cold extreme from three hot extremes and three cold extremes, which were used to invert coefficients $a$ and $b$ for calculating $H$ for each day. Characteristic variables of these extreme pairs are shown in Table 2. $T_{\text {rad,hot }}$ values of hot extremes 1-3 decrease in order; $T_{\text {rad,cold }}$ values of cold extremes 4-6 increase in order. For each day, nine combinations of hot and cold extremes resulted in nine pairs of coefficients $a$ and $b$. Subsequently, they constituted inputs to
SEBAL to compute $H$ and LE for all remaining pixels in the images.

\subsection{Results From SEBAL}

[60] Discrepancies between the estimates of $H$ and LE and EC tower measurements are listed in Table 3. Estimates of all energy balance equation components under nine different combinations of extreme pixels are shown in Figures 9-11 for three study days, respectively. Results indicate that the SEBAL algorithm consistently overestimated $H$ (bias $>0$ ) and underestimated LE (bias $<0$ ) on DOY 174, with an RMSD and MAPD of the $H$ retrievals ranging between $79 \sim 108.3 \mathrm{~W} \mathrm{~m}^{-2}$ and $65 \% \sim 92.6 \%$, respectively, and an RMSD and MAPD of the LE retrievals ranging between $55.4 \sim 81.2 \mathrm{~W} \mathrm{~m}^{-2}$ and $13.5 \% \sim 22.2 \%$, respectively. The underestimation of LE by SEBAL on DOY 174 was likely due to a significant downward shift of cold extremes. SEBAL generally underestimated $H$ and overestimated LE on DOY 182, suggesting an RMSD and MAPD of the $H$ retrievals ranging between $37.4 \sim 51.8 \mathrm{~W} \mathrm{~m}^{-2}$, and $21.0 \% \sim 39.8 \%$, and an RMSD and MAPD of the LE retrievals ranging between $46.2 \sim 60.4 \mathrm{~W} \mathrm{~m}^{-2}$ and $9.8 \% \sim 13.3 \%$, 

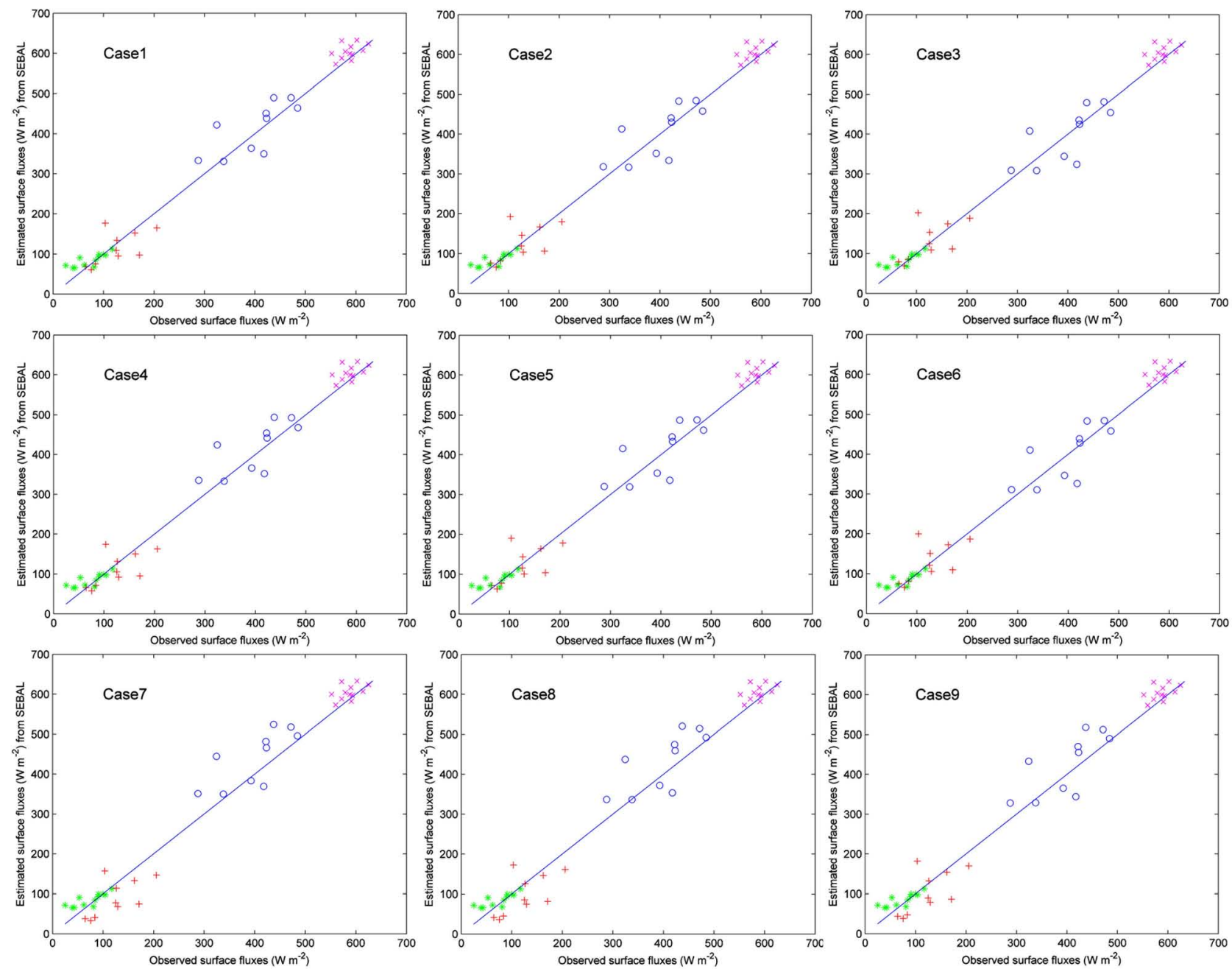

Figure 10. Estimates of $R_{\mathrm{n}}$ (magenta crosses), $G$ (green asterisks), $H$ (red crosses), and LE (blue circles) from SEBAL for nine cases of combinations of selected extremes (see Table 3 ) at the SMACEX site on DOY 182 in 2002.

respectively. A notable overestimation of $H$ from SEBAL was also observed on DOY 189, showing a bias ranging between $0.4 \sim 37.0 \mathrm{~W} \mathrm{~m}^{-2}$ and an unacceptable larger MAPD of the $H$ estimates ranging between $199.3 \% \sim$ $561.8 \%$. The failure of the estimation of $H$ by SEBAL could be ascribed to the presence of advection; the SEBAL algorithm cannot detect advection and therefore quantify $H$. However, the LE estimates from SEBAL on DOY 189 seemed to be acceptable, showing an RMSD ranging between $37.0 \sim 42.3 \mathrm{~W} \mathrm{~m}^{-2}$ and MAPD ranging between $6.6 \% \sim$ $7.3 \%$. These small discrepancies were likely because of a relatively large magnitude of LE on the day; the discrepancies between the estimates and observations tended to be small under large soil wetness conditions.

[61] In general, these discrepancies between the estimates from SEBAL and EC tower measurements appeared to be generally large compared with an RMSD of 39.8 $\mathrm{W} \mathrm{m} \mathrm{m}^{-2}$ and MAPD of $10.3 \%$ on DOY $174,43.3 \mathrm{~W} \mathrm{~m}^{-2}$ and $9.8 \%$ on DOY 182 , and $40.1 \mathrm{~W} \mathrm{~m}^{-2}$ and $6.8 \%$ on DOY 189, respectively, for the LE retrievals from MSEBAL. It is noted that the LE retrievals from SEBAL on DOY 189 under cases 4-6 exhibited smaller discrepancies than M-SEBAL in terms of an MAPD on the order of $\sim 37 \mathrm{~W} \mathrm{~m}^{-2}$ compared to an MAPD of $40.1 \mathrm{~W} \mathrm{~m}^{-2}$ for M-SEBAL. It is, however, important to state that even though in some cases SEBAL could reproduce surface fluxes with slightly higher accuracy at flux tower scales than M-SEBAL, the retrieved fluxes from SEBAL cannot be definitive, varying with selected extremes and subjectivity.

[62] Furthermore, it is noted that the highest accuracy of $H$ and LE retrievals from SEBAL on DOY 174 occurred under case 7 consisting of hot pixel 1 and cold pixel 6 . The combination of hot pixel 1 showing the highest $T_{\text {rad,hot }}$ in three hot extreme candidates and cold pixel 6 showing the highest $T_{\text {rad,cold }}$ in three cold extreme candidates was closest to the trapezoidal framework. In contrast, the lowest accuracy of $H$ and LE retrievals from SEBAL on DOY 174 corresponds to case 3 composed of hot pixel 3 and cold pixel 4, both of which showed the lowest $T_{\text {rad }}$ values in the three respective extreme candidates. Likewise, the lowest accuracy of $H$ and LE retrievals from SEBAL on DOY 182 took place for case 7 (hot pixel 1 and cold pixel 6), which deviated from the trapezoidal framework most. The other six cases, consisting of hot pixels 1 or 2 and cold pixel 4 or 

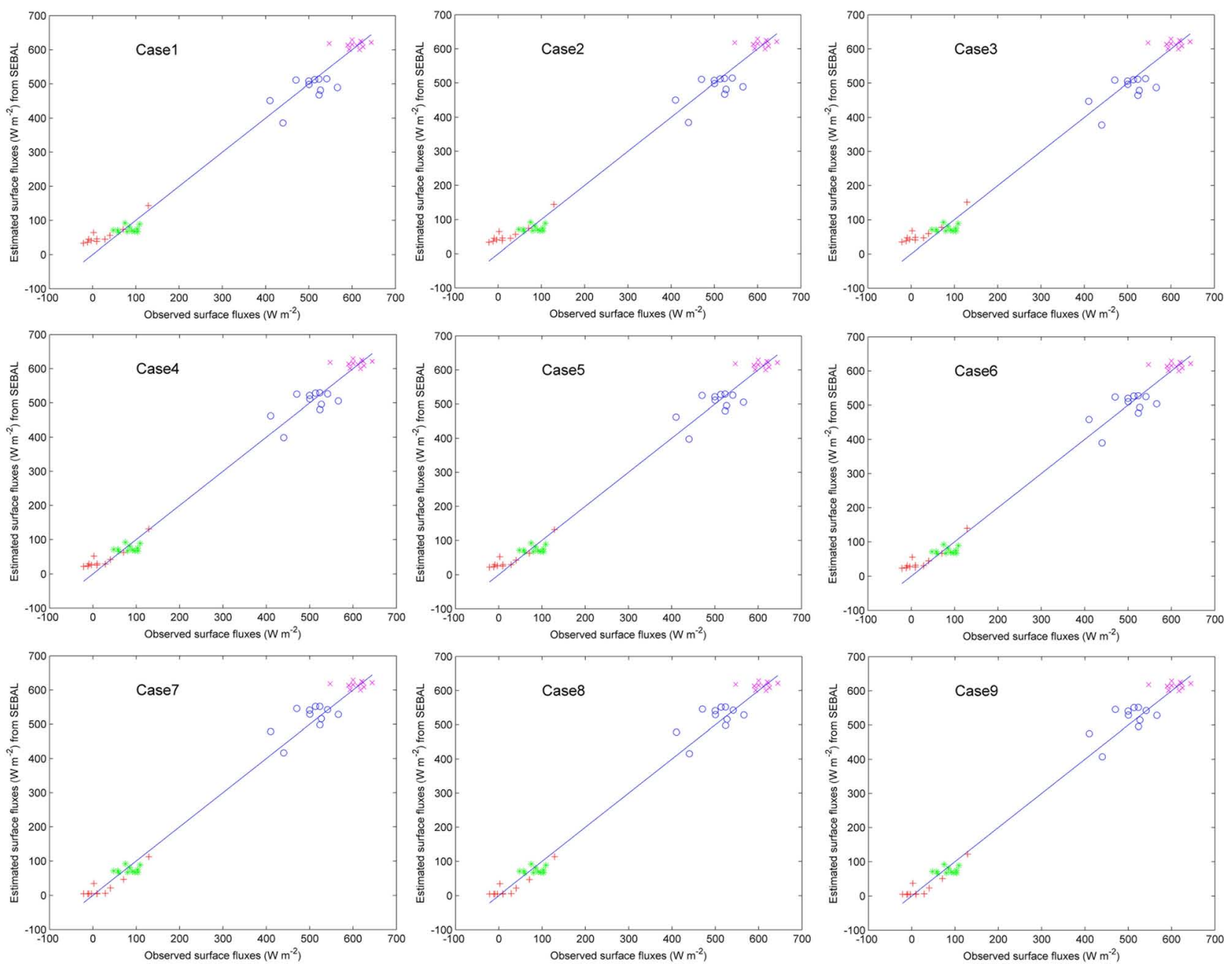

Figure 11. Estimates of $R_{\mathrm{n}}$ (magenta crosses), $G$ (green asterisks), $H$ (red crosses), and LE (blue circles) from SEBAL for nine cases of combinations of selected extremes (see Table 3) at the SMACEX site on DOY 189 in 2002.

5 for SEBAL on DOY 182, exhibited generally similar retrieval accuracy, which was lower than that for M-SEBAL. The largest discrepancies between the model retrievals and EC tower measurements on DOY 189 happened to case 3 (hot pixel 3 and cold pixel 4), which led to a rectangular framework with the largest downward displacement and the largest dissimilarity to the trapezoidal framework. The highest accuracy for $H$ retrievals from SEBAL on DOY 189 took place for cases 7-9 which involved cold pixel 6 . The inclusion of cold pixel 6 made the rectangular framework closest to the cold edge of the trapezoidal framework. Because LE was calculated as the residual of the energy balance equation, the overestimation of both $R_{\mathrm{n}}$ and $H$ for DOY 189 under cases 4-6 tended to be of similar magnitude, thereby resulting in the highest accuracy of the LE estimates compared to other cases (referring to bias for $H$ and LE retrievals on DOY 189 in Table 3).

\subsection{Relationship Between Relative Error and $f_{\mathrm{c}}$ for SEBAL and M-SEBAL}

[63] For unraveling the mechanism of error propagation of SEBAL and M-SEBAL, the relationship between the relative error (simulated $H$-observed $H$ ) in the $H$ estimates from both models and the corresponding $f_{\mathrm{c}}$ values at all EC towers for three test days was investigated. SEBAL was run under the case of the combination of extreme pixels resulting in the best performance of $H$ predictions, i.e., case 7 for DOY 174, case 2 for DOY 182, and case 7 for DOY 189. Results (Figure 12) indicated that for DOY 174, the relative error in the $H$ estimates from SEBAL generally decreased with increasing $f_{\mathrm{c}}$. This was caused principally by a decreasing relative displacement between the rectangular framework in SEBAL and the trapezoidal framework in M-SEBAL. The cold and warm edges of SEBAL were essentially lower than those of the trapezoidal framework for DOY 174, resulting in the increased $H$ and decreased LE estimates. However, with increasing $f_{\mathrm{c}}$ after exceeding the intersection of the theoretical warm edge and the selected hot edge, the selected horizontal hot edge of SEBAL became higher than the slanting one of M-SEBAL, with the overestimation of $H$ from SEBAL being mitigated to a certain degree. On the other hand, even though the $H$ estimates from M-SEBAL also tended to be larger than the measurements, the errors decreased appreciably compared with those of 

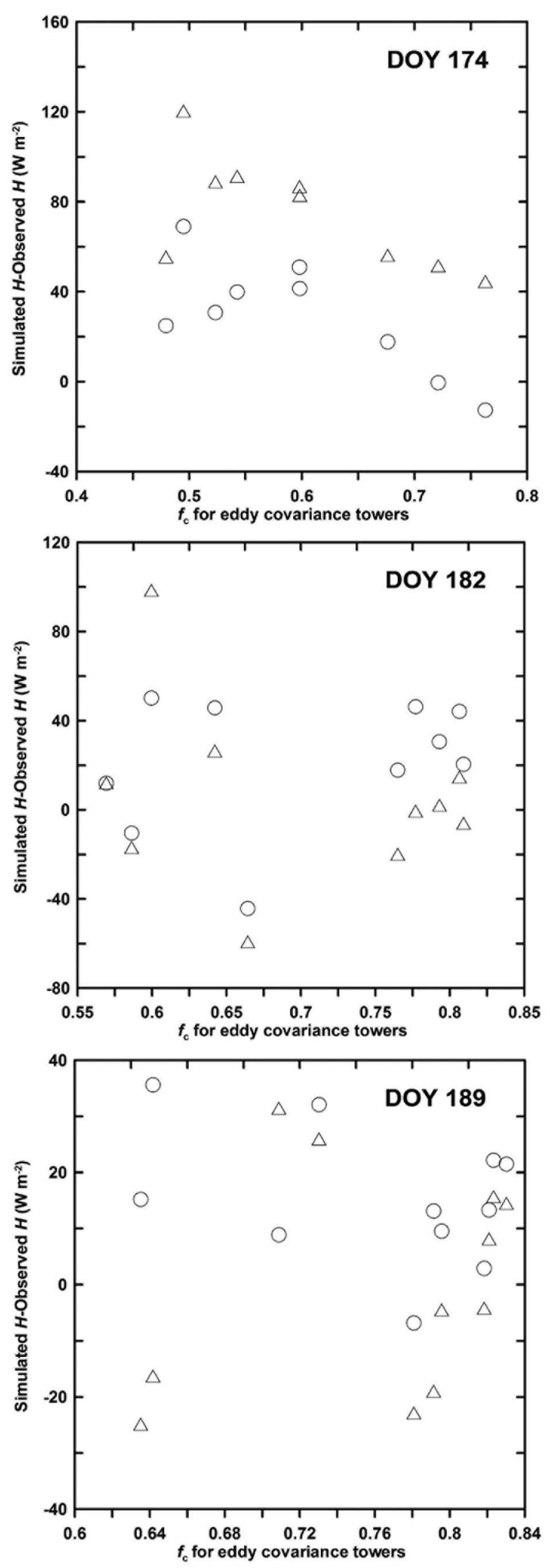

Figure 12. Variation of relative error of $H$ retrievals from SEBAL (triangles) and M-SEBAL (circles) with $f_{\mathrm{c}}$ at the SMACEX site for DOY 174, 182, and 189 in 2002.
SEBAL. This demonstrates that the use of the trapezoidal framework appears to be capable of more realistically reflecting variations in LE with $f_{\mathrm{c}}$ and $T_{\text {rad }}$.

[64] For DOY 182, unfortunately, the whole picture of the mechanisms of error propagation of SEBAL cannot be completely reflected because of limited $f_{\mathrm{c}}$ values generally varying between 0.55 and 0.8 at all EC towers. Errors in the $H$ estimates from SEBAL for high $f_{\mathrm{c}}$ values (i.e., $f_{\mathrm{c}}>0.75$, five towers) tended to be smaller than those of M-SEBAL, which may result from a good approximation of the rectangular framework to the realistic boundaries. However, relative errors in the $H$ estimates from SEBAL for $f_{\mathrm{c}}<0.7$ (five sites) were generally larger than those of M-SEBAL. DOY 189 did not seem to exhibit any trend in the relative error of the $H$ estimates due to the influence of advection. SEBAL appeared to reproduce $H$ with higher accuracy compared to M-SEBAL under case 7 at those EC towers.

\subsection{Spatial Distribution of $\boldsymbol{H}$ and LE Retrievals From SEBAL and M-SEBAL}

[65] Figures 13 and 14 show spatial distributions and frequencies of $H$ and LE estimates across the SMACEX site from SEBAL and M-SEBAL. Coefficients $a$ and $b$ for SEBAL were derived from the combination of extreme pixels which resulted in the best performance of the $H$ estimation illustrated in section 5.4. Results explicitly showed that SEBAL generated significantly larger $H$ fluxes than M-SEBAL on DOYs 174 and 182, showing spatial mean of the $H$ estimates from SEBAL and M-SEBAL of 208.5 $\mathrm{W} \mathrm{m} \mathrm{m}^{-2}$ and $166.2 \mathrm{~W} \mathrm{~m}^{-2}$ on DOY 174 , and $306.4 \mathrm{~W} \mathrm{~m}^{-2}$ and $164.6 \mathrm{~W} \mathrm{~m}^{-2}$ on DOY 182 , respectively. The overestimation of $H$ estimates from SEBAL was due primarily to its downward shifted rectangular framework. The downward shift of the cold edge (case 7, cold pixel 6) for DOY 174 and the downward shift of the hot edge (case 2, hot pixel 2) for DOY 182 could be responsible for the overestimation of the areal $H$ estimates, particularly for lower $f_{\mathrm{c}}$ areas. In fact, $\sim 5.4 \%$ area of the study site for DOY 182 showed the $H$ estimates from SEBAL were larger than the available energy $\left(R_{\mathrm{n}}-G\right)$ (see the relative frequency and cumulative distribution of LE in row 3 in Figure 14). These could be erroneous $H$ retrievals from SEBAL, even under the condition of an overestimation of $R_{\mathrm{n}}$ (bias: $18.1 \mathrm{~W} \mathrm{~m}^{-2}$, referring to Table 1); thereby, the LE retrievals from SEBAL were artificially set to zero for these pixels and some portions of the LE map suffer from this artifact. In addition, there were $8.4 \%$ pixels whose $H$ estimates from SEBAL for DOY 189 were set to zero. This is because $T_{\text {rad }}$ values of these pixels were smaller than the $T_{\text {rad }}$ of the cold pixel (case 7, cold pixel 6) taken for DOY 189 (see Figure 8). On the contrary, the $H$ estimates from SEBAL on DOY 189 were generally smaller than M-SEBAL, showing a spatial mean of $42.0 \mathrm{~W}$ $\mathrm{m}^{-2}$ and $73.1 \mathrm{~W} \mathrm{~m}^{-2}$, respectively. This difference resulted mostly from a higher-horizontal hot edge for SEBAL (case 7, hot pixel 1) compared with the theoretical warm edge. Therefore, the $H$ estimates from SEBAL tended to be smaller and then the LE estimates tended to be larger than M-SEBAL.

[66] On the other hand, there were $\sim 4 \%$ pixels and $8 \%$ pixels whose $H$ retrievals from M-SEBAL were postprocessed to be zero for DOY 174 and DOY 189, respectively (see the relative frequency and cumulative distribution of 

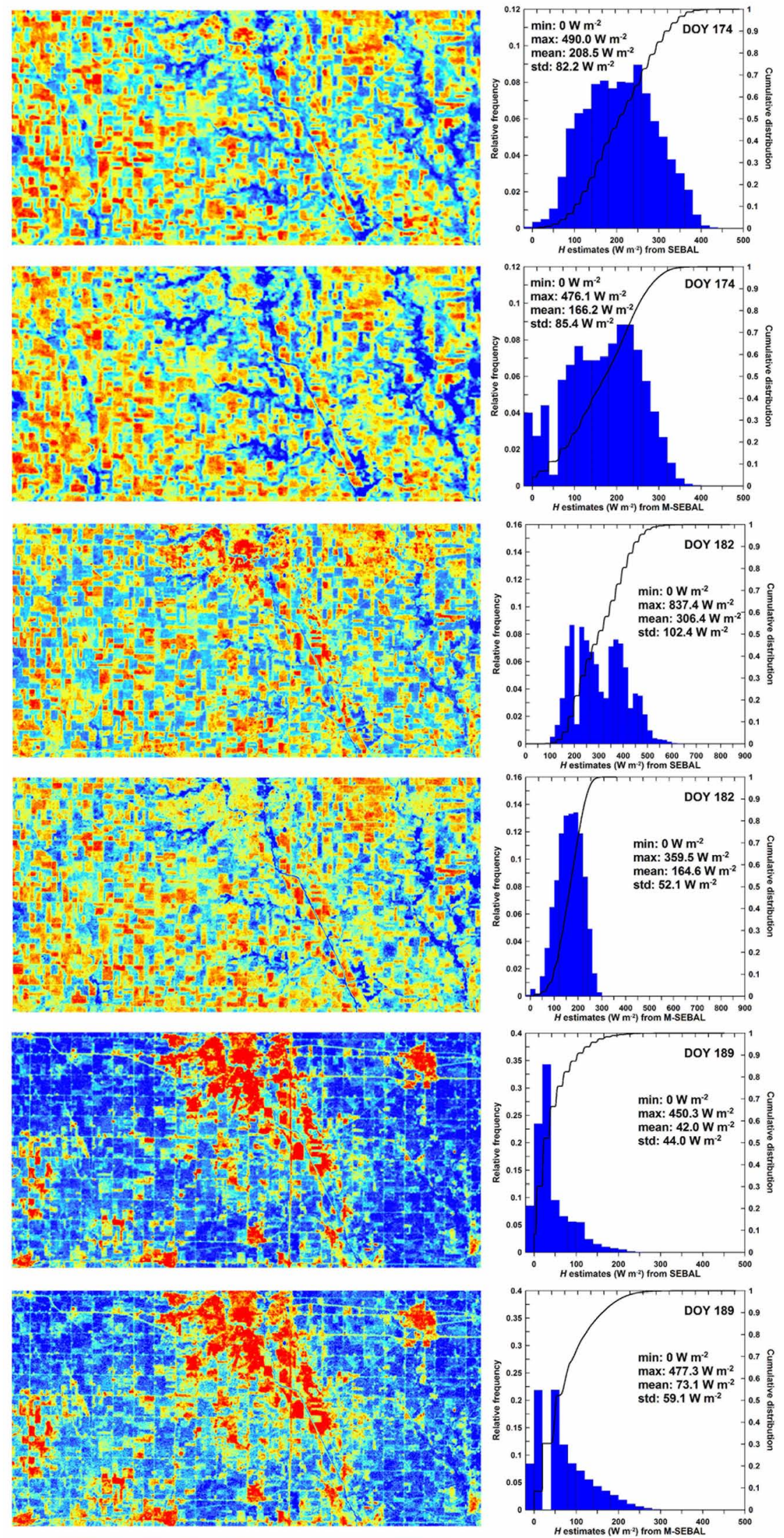

840 Sensible heat flux $\left(\mathrm{W} \mathrm{m}^{-2}\right)$

Figure 13 
$H$ in rows 2 and 6 in Figure 13), which resulted from the cold edge of M-SEBAL being taken as $T_{\mathrm{a}}$. There was also a cluster of pixels whose $T_{\text {rad }}$ values were lower than $T_{\mathrm{a}}$ due to cloud, terrain, and other effects. Thereby, the $H$ values of those pixels were postprocessed to be zero. However, the $H$ estimates of those pixels were mistakenly derived as small magnitudes by the SEBAL algorithm due to unrealistic cold pixels identified.

[67] In summary, directly relating $T_{\text {rad }}$ retrievals to LE throughout a scene based on a unique linear relationship in SEBAL can be unreasonable in generating large-scale LE, even though a good agreement between the flux estimates and measurements at a handful of towers may be observed and reported. Distributions of $H$ and LE from SEBAL may have been distorted to varying degrees due to the oversimplified rectangular framework in previous applications. The degree of distortion depends on the theoretical boundaries, manually identified extremes, and outliers in $T_{\text {rad }}$ retrievals. Mapping ET by SEBAL seems to be of large uncertainty due to the oversimplified rectangular framework it intrinsically involves and the determination of end members of large uncertainty. The end members are greatly susceptible to uncertainties/outliers in $T_{\text {rad }}$ retrievals. The M-SEBAL algorithm appears to be capable of reproducing reasonable LE distribution due to the integration of a physically meaningful trapezoidal framework.

\section{Model Advantages and Limitations of M-SEBAL}

[68] Evaluation of M-SEBAL at the SMACEX site for three Landsat TM/ETM ${ }^{+}$imagery acquisition dates in 2002 demonstrates that M-SEBAL generally reproduces $H$ and LE fluxes with an RMSD on the order of $\sim 30 \mathrm{~W} \mathrm{~m}^{-2}$ and $\sim 40 \mathrm{~W} \mathrm{~m}^{-2}$, respectively, which show a closer agreement with EC tower measurements than SEBAL. More importantly, it reduces ambiguity and uncertainty in the LE estimation due to the differing extremes possibly selected by the operator. The most prominent attribute of M-SEBAL is the use of a physically meaningful trapezoidal framework to account for the effect of variations in $f_{\mathrm{c}}$ and $T_{\mathrm{rad}}$ on flux estimation. Specifically:

[69] 1. M-SEBAL does not need to visually identify two end members from the satellite image as SEBAL. It takes advantage of a physically meaningful trapezoidal framework, which can contextually interpret impacts of variations in $f_{\mathrm{c}}$ and $T_{\text {rad }}$ on flux estimation. The theoretical hot edge of the trapezoidal framework is analytically derived by solving for temperatures of the bare surface with the largest water stress and the fully vegetated surface with the largest water stress implicit in both energy balance and radiation budget equations, given certain meteorological conditions and surface properties. The cold edge of the trapezoidal framework makes use of observed areally averaged $T_{\mathrm{a}}$, which seems to be able to obviate uncertainties in $T_{\text {rad }}$ retrievals due to cloud and terrain effects.

[70] 2. Coefficients $a$ and $b$, to determine temperature difference in the $H$ algorithm in M-SEBAL, can vary with $f_{\mathrm{c}}$, rather than a constant pair in SEBAL. The varied coefficients $a$ and $b$ provide a mechanism to reflect the realistic boundaries of the $f_{\mathrm{c}}-T_{\mathrm{rad}}$ space and therefore confine LE estimates to reasonable magnitudes for surfaces of generic $T_{\text {rad }}$ values.

[71] 3. The data requirement of M-SEBAL can readily be met, involving routinely observed meteorological variables and remotely sensed $f_{\mathrm{c}}, \alpha$, and $T_{\text {rad }}$. MODIS-based atmospheric data products can be tentatively used to provide $T_{\mathrm{a}}$ and $e_{\mathrm{a}}$ in the surface layer. In addition, M-SEBAL makes use of information contained in contextual $f_{\mathrm{c}}-T_{\text {rad }}$, $f_{\mathrm{c}}-\alpha$, and $f_{\mathrm{c}}-\Delta E$ spaces to infer relevant variables and parameters involved in the trapezoidal framework, which gives a full role to inherent spatial information among remotely sensed surface variables and therefore creates an opportunity to reflect spatially meaningful ET across large areas. M-SEBAL does not greatly increase the input requirement compared with SEBAL.

[72] As with other satellite-based ET models, M-SEBAL has certain limitations because of the following involved assumptions:

[73] 1. M-SEBAL does not involve a mechanism to explicitly account for the effects of advection on flux estimation. However, the use of $T_{\mathrm{a}}$ to be the cold edge of the trapezoidal framework could tentatively detect surfaces suffering from advection (i.e., $T_{\mathrm{rad}}<T_{\mathrm{a}}$, under $\operatorname{high} f_{\mathrm{c}}$ conditions $T_{\text {rad }}$ can be a reasonable substitution of aerodynamic temperature), cloud contamination, and terrain effects. Estimation of LE for these surfaces can be independently performed using other approaches.

[74] 2. The use of $T_{\mathrm{a}}$ as the cold edge would result in the underestimation of LE for low $f_{\mathrm{c}}$ areas. This treatment is, however, an operational way to demarcate the lower boundary of the trapezoidal framework. Otherwise, determination of the cold boundary/pixel is often influenced by clouds, outliers in $T_{\text {rad }}$ retrievals, and the spatial resolution and domain size of satellite images.

\section{Conclusions}

[75] Aiming to reduce ambiguity in SEBAL-based ET estimation due to the subjectivity in the selection of extreme pixels, this study first demonstrates that SEBAL is of a rectangular framework of the vegetation fraction $\left(f_{\mathrm{c}}\right)$ and surface radiative temperature $\left(T_{\mathrm{rad}}\right)$ space. The hot and cold pixels constitute, essentially, two boundaries of the rectangular framework, which appear to distort the spatial distribution of $H$ and LE retrievals to varying degrees. The modified surface energy balance algorithm for land (MSEBAL) is proposed, which involves a physically meaningful trapezoidal framework of the $f_{\mathrm{c}}$ and $T_{\text {rad }}$ space. The warm edge of the trapezoidal framework is analytically derived by solving for temperatures of the bare surface with the largest water stress and the fully vegetated surface, with the largest water stress implicit in both the energy balance and radiation budget equations. Areally averaged air temperature across a scene is taken to be the cold edge of the trapezoidal framework. Each pixel or pixels within the

Figure 13. Maps, frequency distributions, and cumulative curves of $H$ estimates from SEBAL and M-SEBAL on DOY 174,182 , and 189 in 2002. A bin size of $20 \mathrm{~W} \mathrm{~m}^{-2}$ for the frequency distributions was specified. Spatial minimum (min), maximum (max), mean, and standard deviation (std) of the $H$ estimates are given. 

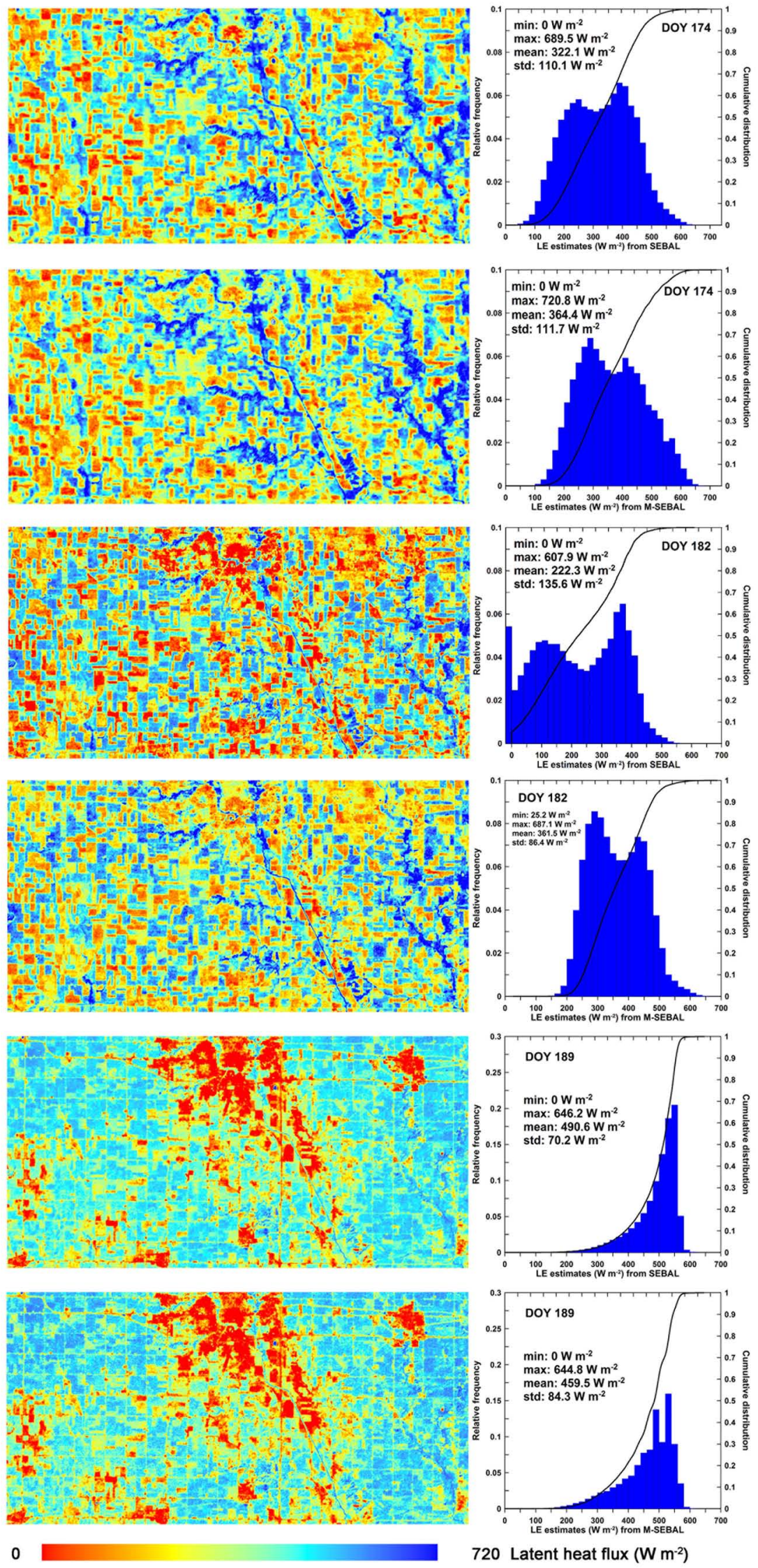

Figure 14 
same $f_{\mathrm{c}}$ class have a specific pair of coefficients, $a$ and $b$, rather than a constant pair of $a$ and $b$ in SEBAL to determine the difference between the aerodynamic temperature and the air temperature across a scene.

[76] SEBAL and M-SEBAL are applied to the soil moisture-atmosphere coupling experiment (SMACEX) site in central Iowa. Results show that M-SEBAL is capable of reproducing LE reasonably well, showing an overall RMSE of $41.1 \mathrm{~W} \mathrm{~m}^{-2}$ and an MAPD of $8.9 \%$ for three Landsat $\mathrm{TM} / \mathrm{ETM}^{+}$imagery acquisition dates in 2002. The retrieval accuracy of SEBAL is generally lower than M-SEBAL, with discrepancies depending largely on the selected extremes. In addition, the spatial distributions of $H$ and LE retrievals from SEBAL are distorted to varying degrees due to its intrinsic rectangular framework. The use of the trapezoidal framework in M-SEBAL can ensure a more reasonable distribution of $H$ and LE across the study site and address the ambiguity in LE estimation due to subjectivity in end member selection and uncertainty in $T_{\text {rad }}$ retrievals.

\section{Appendix A}

[77] Formulas for calculating $f_{\mathrm{c}}, \varepsilon_{\lambda}$, and statistical measures of RMSD, MAPD, and Bias.

$$
f_{\mathrm{c}}=1-\left(\frac{\mathrm{NDVI}_{\mathrm{max}}-\mathrm{NDVI}}{\mathrm{NDVI}_{\mathrm{max}}-\mathrm{NDVI}_{\mathrm{min}}}\right)^{a},
$$

where $\mathrm{NDVI}_{\text {max }}$ and $\mathrm{NDVI}_{\text {min }}$ denote the maximum and minimum values of NDVI. Parameter $a$ is taken as 0.625 in this study.

$$
\varepsilon_{\lambda}=\varepsilon_{\mathrm{c}} f_{\mathrm{c}}+\varepsilon_{\mathrm{s}}\left(1-f_{\mathrm{c}}\right),
$$

where $\varepsilon_{\lambda}$ is the narrow band emissivity (dimensionless), $\varepsilon_{\mathrm{c}}$ is the vegetation emissivity (taking the average of a typical value 0.985 ), and $\varepsilon_{\mathrm{s}}$ is the soil emissivity (taking the average of a typical value 0.978 based on laboratory analysis of soil samples collected in the watershed) [Li et al., 2004].

$$
\begin{gathered}
\mathrm{RMSD}=\left[\frac{1}{n} \sum_{i=1}^{n}\left(P_{i}-Q_{i}\right)^{2}\right]^{1 / 2}, \\
\mathrm{MAPD}=100 \times \frac{1}{n} \sum_{i=1}^{n}\left|\frac{P_{i}-Q_{i}}{Q_{i}}\right|, \\
\operatorname{Bias}=\sum_{i=1}^{n}\left(P_{i}-O_{i}\right),
\end{gathered}
$$

where $n$ is the number of samples, $P_{i}$ represents the prediction value, and $O_{i}$ represents the observed value.

\section{Appendix B}

[78] Formulas for calculating $r_{\mathrm{a}, \mathrm{s}}$ and $r_{\mathrm{a}, \mathrm{c}}$ for points $\mathrm{A}$ and $\mathrm{D}$ in the trapezoidal framework in M-SEBAL

$$
r_{\mathrm{a}, \mathrm{s}}=\frac{1}{0.0015 u_{1 \mathrm{~m}}}
$$

$$
u=\frac{u_{*}}{\mathrm{k}}\left[\ln \frac{\left(z_{\mathrm{m}}-d\right)}{z_{\mathrm{om}}}-\psi_{\mathrm{m}(1)}+\psi_{\mathrm{m}\left(z_{\mathrm{om}}\right)}\right] .
$$

1. Unstable conditions $(L<0)$ :

$$
\begin{gathered}
\psi_{\mathrm{m}(1)}=2 \ln \left(\frac{1+x_{[1]}}{2}\right)+\ln \left(\frac{1+x_{[1]}^{2}}{2}\right)-2 \arctan \left(x_{[1]}\right)+0.5 \pi \\
\psi_{\mathrm{m}\left(z_{\mathrm{om}}\right)}=2 \ln \left(\frac{1+x_{\left[z_{\mathrm{om}}\right]}}{2}\right)+\ln \left(\frac{1+x_{\left[z_{\mathrm{om}}\right]}^{2}}{2}\right)-2 \arctan \left(x_{\left[z_{\mathrm{om}}\right]}\right)+0.5 \pi, \\
x_{(1)}=\left(1-16 \frac{1}{L}\right)^{0.25}, \\
x_{\left(z_{\mathrm{om}}\right)}=\left(1-16 \frac{z_{\mathrm{om}}}{L}\right)^{0.25}, \\
L=-\frac{\rho \mathrm{c}_{\mathrm{p}} u_{*}^{3} T_{\mathrm{a}}}{\mathrm{kg} H_{\mathrm{s}}} .
\end{gathered}
$$

2. Stable conditions $(L>0)$ :

$$
\begin{gathered}
\psi_{\mathrm{m}(1)}=-5\left(\frac{1}{L}\right), \\
\psi_{\mathrm{m}\left(z_{\mathrm{om}}\right)}=-5\left(\frac{z_{\mathrm{om}}}{L}\right),
\end{gathered}
$$

where $u_{1 \mathrm{~m}}$ is the wind velocity at $1 \mathrm{~m}$ height above the bare soil surface $\left(\mathrm{m} \mathrm{s}^{-1}\right)$; equation (B2) is the logarithmic wind profile function, in which $u_{*}$ is the friction velocity $\left(\mathrm{m} \mathrm{s}^{-1}\right)$, $\mathrm{k}$ is the von Karman's constant $(0.41), z_{\mathrm{m}}$ is the reference height for wind velocity observations ( $1 \mathrm{~m}$ for the bare soil surface), $d$ is the zero plane displacement $(\mathrm{m})$ ( 0 for the bare soil surface), and $z_{\text {om }}$ is the roughness length for momentum transfer $(\mathrm{m})$. For the bare soil surface, $z_{\text {om }}$ can be typically taken as $0.005 \mathrm{~m}$ [e.g., Allen et al., 2007; Nishida et al., 2003]. $\psi_{\mathrm{m}(1)}$ and $\psi_{\mathrm{m}\left(z_{\mathrm{om}}\right)}$ are the stability correction factors at $1 \mathrm{~m}$ and $0.005 \mathrm{~m}$ height for the bare soil surface (dimensionless), respectively. $L$ is the Monin-Obukhov length $(\mathrm{m})$ and $g$ is the acceleration of gravity $\left(9.8 \mathrm{~m} \mathrm{~s}^{-2}\right)$.

[79] For $r_{\mathrm{a}, \mathrm{c}}$,

$$
\begin{gathered}
r_{\mathrm{a}, \mathrm{c}}=\frac{\ln \left(\frac{z_{\mathrm{T}}-d}{z_{\mathrm{oh}}}\right)-\psi_{\mathrm{h}\left(\mathrm{z}_{\mathrm{T}}\right)}+\psi_{\mathrm{h}\left(z_{\mathrm{oh}}\right)}}{u_{*} \mathrm{k}} \\
u=\frac{u_{*}}{\mathrm{k}}\left[\ln \frac{\left(z_{\mathrm{m}}-d\right)}{z_{\mathrm{om}}}-\psi_{\mathrm{m}\left(z_{\mathrm{m}}\right)}+\psi_{\mathrm{m}\left(z_{\mathrm{om}}\right)}\right] .
\end{gathered}
$$

1. Unstable conditions $(L<0)$ :

$$
\psi_{\mathrm{m}\left(z_{\mathrm{m}}\right)}=2 \ln \left(\frac{1+x_{\left[z_{\mathrm{m}}\right]}}{2}\right)+\ln \left(\frac{1+x_{\left[z_{\mathrm{m}}\right]}^{2}}{2}\right)-2 \arctan \left(x_{\left[z_{\mathrm{m}}\right]}\right)+0.5 \pi,
$$

Figure 14. Maps, frequency distributions, and cumulative curves of LE estimates from SEBAL and M-SEBAL on DOY 174,182 , and 189 in 2002 . A bin size of $20 \mathrm{~W} \mathrm{~m}^{-2}$ for the frequency distributions was specified. Spatial minimum (min), maximum (max), mean, and standard deviation (std) of the $H$ estimates are given. 


$$
\psi_{\mathrm{m}\left(z_{\mathrm{om}}\right)}=2 \ln \left(\frac{1+x_{\left[z_{\mathrm{om}}\right]}}{2}\right)+\ln \left(\frac{1+x_{\left[z_{\mathrm{om}}\right]}^{2}}{2}\right)-2 \arctan \left(x_{\left[z_{\mathrm{om}}\right]}\right)+0.5 \pi
$$

$$
\begin{aligned}
\psi_{\mathrm{h}\left(z_{\mathrm{T}}\right)} & =2 \ln \left(\frac{1+x_{\left[\mathrm{z}_{\mathrm{T}}\right]}^{2}}{2}\right), \\
\psi_{\mathrm{h}\left(z_{\mathrm{oh}}\right)} & =2 \ln \left(\frac{1+x_{\left[z_{\mathrm{oh}}\right]}^{2}}{2}\right), \\
x_{\left(z_{\mathrm{m}}\right)} & =\left(1-16 \frac{z_{\mathrm{m}}}{L}\right)^{0.25}, \\
x_{\left(z_{\mathrm{om}}\right)} & =\left(1-16 \frac{z_{\mathrm{om}}}{L}\right)^{0.25}, \\
x_{\left(z_{\mathrm{T}}\right)} & =\left(1-16 \frac{z_{\mathrm{T}}}{L}\right)^{0.25}, \\
x_{\left(z_{\mathrm{oh}}\right)} & =\left(1-16 \frac{z_{\mathrm{oh}}}{L}\right)^{0.25}, \\
L & =-\frac{\rho \mathrm{c}_{\mathrm{p}} u_{*}^{3} T_{\mathrm{a}}}{\mathrm{kg} g H_{\mathrm{c}}} .
\end{aligned}
$$

2. Stable conditions $(L>0)$ :

$$
\begin{aligned}
& \psi_{\mathrm{m}\left(z_{\mathrm{m}}\right)}=-5\left(\frac{z_{\mathrm{m}}}{L}\right), \\
& \psi_{\mathrm{m}\left(z_{\mathrm{om}}\right)}=-5\left(\frac{z_{\mathrm{om}}}{L}\right), \\
& \psi_{\mathrm{h}\left(z_{\mathrm{T}}\right)}=-5\left(\frac{z_{\mathrm{T}}}{L}\right), \\
& \psi_{\mathrm{h}\left(z_{\mathrm{oh}}\right)}=-5\left(\frac{z_{\mathrm{oh}}}{L}\right),
\end{aligned}
$$

where, $z_{\mathrm{T}}$ is the reference height for temperature observation, which is taken to be $2 \mathrm{~m}$ for the study site. The driest fully vegetated surface is assumed to have a vegetation height $h_{\mathrm{c}}=1 \mathrm{~m}$. The zero plane displacement $d, z_{\mathrm{om}}$, and $z_{\mathrm{oh}}$ for the hypothesized vegetated surface can then be specified as $d=2 h_{\mathrm{c}} / 3, z_{\mathrm{om}}=h_{\mathrm{c}} / 10$, and $z_{\mathrm{oh}}=z_{\mathrm{om}} / 7$ [Garratt and Hicks, 1973]. It is noted that if $u_{*}$ that has been corrected by $\psi_{\mathrm{m}(\mathrm{zm})}$ and $\psi_{\mathrm{m} \text { (zom) }}$ is obtained from weather stations, equation (B11) just needs to perform the stability correction by $\psi_{\mathrm{h}(\mathrm{zT})}$ and $\psi_{\mathrm{h}(\mathrm{zoh})}$.

[80] Acknowledgments. We greatly thank the National Snow and Ice Data Center for providing the SMACEX data sets to evaluate the developed model. All people involved in the field campaign are gratefully acknowledged. The authors are grateful to the associate editor and four referees who provided thorough and constructive reviews. This work was financially supported by the United States Geological Survey (USGS, project 2009TX334G).

\section{References}

Ahmed, B. M., H. Tanakamaru, and A. Tada (2010), Application of remote sensing for estimating crop water requirements, yield and water productivity of wheat in the Gezira Scheme, Int. J. Remote Sens., 31(16), 42814294 .
Allen, R. G., M. Tasumi, and R. Trezza (2007), Satellite-based energy balance for mapping evapotranspiration with internalized calibration (METRIC)-model, J. Irrig. Drain. Eng., 133(4), 380-394.

Anderson, M. C., J. M. Norman, W. P. Kustas, F. Li, J. H. Prueger, and J. R. Mecikalski (2005), Effects of vegetation clumping on two-source model estimates of surface energy fluxes from an agricultural landscape during SMACEX, J. Hydrometeorol., 6(6), 892-909.

Anderson, M. C., J. M. Norman, J. R. Mecikalski, J. A. Otkin, and W. P. Kustas (2007), A climatological study of evapotranspiration and moisture stress across the continental United States based on thermal remote sensing: 1. Model formulation, J. Geophys. Res. Atmos. 112(D10), D10117.

Bashir, M. A., H. Tanakamaru, and A. Tada (2009), Spatial and temporal analysis of evapotranspiration using satellite remote sensing data: A case study in the Gezira Scheme, Sudan, J. Environ. Inform., 13(2), 86-92.

Bastiaanssen, W. G. M. (2000), SEBAL-based sensible and latent heat fluxes in the irrigated Gediz Basin, Turkey, J. Hydrol., 229(1-2), 87-100.

Bastiaanssen, W. G. M., M. Menenti, R. A. Feddes, and A. A. M. Holtslag (1998), A remote sensing surface energy balance algorithm for land (SEBAL) 1. Formulation, J. Hydrol., 213(1-4), 198-212.

Bastiaanssen, W. G. M., M.-D. Ahmad, and Y. Chemin (2002), Satellite surveillance of evaporative depletion across the Indus Basin, Water Resour. Res., 38(12), 1273, doi:10.1029/2001WR000386.

Bastiaanssen, W. G. M., E. J. M. Noordman, H. Pelgrum, G. Davids, B. P. Thoreson, and R. G. Allen (2005), SEBAL model with remotely sensed data to improve water-resources management under actual field conditions, J. Irrig. Drain. Eng., 131(1), 85-93.

Bastiaanssen, W. G. M., B. Thoreson, B. Clark, and G. Davids (2010), Discussion of "Application of SEBAL model for mapping evapotranspiration and estimating surface energy fluxes in South-Central Nebraska" by Ramesh K. Singh, Ayse Irmak, Suat Irmak, and Derrel L. Martin, J. Irrig. Drain. Eng., 136(4), 282-283.

Berk, A., L. S. Bernstein, G. P. Anderson, P. K. Acharya, D. C. Robertson, J. H. Chetwynd, and S. M. Adler-Golden (1998), MODTRAN cloud and multiple scattering upgrades with application to AVIRIS, Remote Sens. Environ., 65(3), 367-375.

Brutsaert, W. (1975), Derivable formula for long-wave radiation from clear skies, Water Resour. Res. 11(5), 742-744.

Carlson, T. (2007), An overview of the "triangle method" for estimating surface evapotranspiration and soil moisture from satellite imagery, Sensors, 7(8), 1612-1629.

Chavez, J. L., C. M. U. Neale, L. E. Hipps, J. H. Prueger, and W. P. Kustas (2005), Comparing aircraft-based remotely sensed energy balance fluxes with eddy covariance tower data using heat flux source area functions, J. Hydrometeorol., 6(6), 923-940.

Choi, M., W. P. Kustas, M. C. Anderson, R. G. Allen, F. Li, and J. H. Kjaersgaard (2009), An intercomparison of three remote sensing-based surface energy balance algorithms over a corn and soybean production region (Iowa, US) during SMACEX, Agric. Forest Meteorol., 149(12), 2082-2097.

Compaoré, H., J. M. H. Hendricks, S.-H. Hong, J. Friesen, N. C. van de Giesen, C. Rodgers, J. Szarzynski, and P. L. G. Vlek (2008), Evaporation mapping at two scales using optical imagery in the White Volta Basin, Upper East Ghana, Phys. Chem. Earth, 33(1-2), 127-140.

Courault, D., et al. (2009), Influence of agricultural practices on micrometerological spatial variations at local and regional scales, Int. J. Remote Sens., 30(5), 118-1205.

Cristóbal, J., J. C. Jiménez-Muñoz, J. A. Sobrino, M. Ninyerola, and $\mathrm{X}$. Pons (2009), Improvements in land surface temperature retrieval from the Landsat series thermal band using water vapor and air temperature, J. Geophys. Res. Atmos., 114, D08103.

Folhes, M. T., C. D. Rennó, and J. V. Soares (2009), Remote sensing for irrigation water management in the semi-arid Northeast of Brazil, Agric. Water Manage., 96(10), 1398-1408.

French, A. N., et al. (2005a), Surface energy fluxes with the advanced spaceborne thermal emission and reflection radiometer (ASTER) at the Iowa 2002 SMACEX site (USA), Remote Sens. Environ, 99(1-2), 55-65.

French, A. N., F. Jacob, M. Anderson, W. Kustas, W. Timmermans, A. Gieske, Z. Su, H. Su, M. McCabe, F. Li (2005b), Corrigendum to "Surface energy fluxes with the advanced spaceborne thermal emission and reflection radiometer (ASTER) at the Iowa 2002 SMACEX site (USA) (vol. 99, pg, 55, 2005)," Remote Sens. Environ., 99(4), 471-471.

Gao, Y. C., D. Long, and Z.-L. Li (2008), Estimation of daily actual evapotranspiration from remotely sensed data under complex terrain over the upper Chao river basin in North China, Int. J. Remote Sens., 29(11), 3295-3315. 
Garratt, J. R., and B. B. Hicks (1973), Momentum, heat and water vapour transfer to and from natural and artificial surfaces, $Q . J$. R. Meteorol. Soc., 99(422), 680-687.

Garrison, J. D., and G. P. Adler (1990), Estimation of precipitable water over the United States for application to the division of solar-radiation into its direct and diffuse components, Solar Energy, 44(4), 225-241.

Gillies, R. R., T. N. Carlson, J. Cui, W. P. Kustas, and K. S. Humes (1997), A verification of the "triangle" method for obtaining surface soil water content and energy fluxes from remote measurements of the normalized difference vegetation index (NDVI) and surface radiant temperature, Int. J. Remote Sens., 18(15), 3145-3166.

Gonzalez-Dugo, M. P., C. M. U. Neale, L. Mateos, W. P. Kustas, J. H. Prueger, M. C. Anderson, and F. Li (2009), A comparison of operational remote sensing-based models for estimating crop evapotranspiration, Agric. Forest Meteorol., 149(11), 1843-1853.

Jackson, R. D., S. B. Idso, R. J. Reginato, and P. J. Pinter Jr. (1981), Canopy temperature as a crop water stress indicator, Water Resour. Res., 17(4), 1133-1138.

Jiang, L., and S. Islam (2001), Estimation of surface evaporation map over southern Great Plains using remote sensing data, Water Resour. Res., 37(2), 329-340.

Jiang, L., S. Islam, W. Guo, A. S. Jutla, S. U. S. Senarath, B. H. Ramsay, and E. Eltahir (2009), A satellite-based daily actual evapotranspiration estimation algorithm over South Florida, Global Planet. Change, 67(1-2), 62-77.

Kalma, J. D., T. R. McVicar, and M. F. McCabe (2008), Estimating land surface evaporation: A review of methods using remotely sensed surface temperature data, Surv. Geophys., 29(4-5), 421-469.

Karatas, B. S., E. Akkuzu, H. B. Unal, S. Asik, and M. Avci (2009), Using satellite remote sensing to assess irrigation performance in water user associations in the Lower Gediz Basin, Turkey, Agric. Water Manage., 96(6), 982-990.

Kleissl, J., S.-H. Hong, and J. M. H. Hendrickx (2009), New Mexico scintillometer network supporting remote sensing and hydrologic and meteorological models, Bull. Amer. Meteorol. Soc. 90(2), 207-218.

Kondo, J. (1994), Meteorology of Water Environment, 350 pp., Asakurashoten, Tokyo, Japan.

Kustas, W., and M. Anderson (2009), Advances in thermal infrared remote sensing for land surface modeling, Agr. Forest Meteorol., 149(12), 20712081.

Kustas, W. P., P. J. L. Hatfield, and J. H. Pruege (2005), The soil moistureatmosphere coupling experiment (SMACEX): Background, hydrometeorological conditions, and preliminary findings, J. Hydrometeorol., 6(6), 791-804.

Li, F., T. J. Jackson, W. P. Kustas, T. J. Schmugge, A. N. French, M. H. Cosh, and R. Bindlish (2004), Deriving land surface temperature from Landsat 5 and 7 during SMEX02/SMACEX, Remote Sens. Environ., 92(4), 521-534.

Li, F., W. Kustas, J. PRueger, C. Neale, and T. Jackson (2005), Utility of remote sensing-based two-source energy balance model under low- and high-vegetation cover conditions, J. Hydrometeorol., 6(6), 878-891.

Li, S. B., and W. Z. Zhao (2010), Satellite-based actual evapotranspiration estimation in the middle reach of the Heihe River Basin using the SEBAL method, Hydrol. Processes, 24(23), 3337-3344.

Long, D., and V. P. Singh (2010), Integration of the GG model with SEBAL to produce time series of evapotranspiration of high spatial resolution at watershed scales, J. Geophys. Res.Atmos., 115, D21128.

Long, D., Y. Gao, and V. P. Singh (2010), Estimation of daily average net radiation from MODIS data and DEM over the Baiyangdian watershed in North China for clear sky days, J. Hydrol., 388(3-4), 217-233.

Long, D., V. P. Singh, and Z.-L. Li (2011), How sensitive is SEBAL to changes in input variables, domain size and satellite sensor?, J. Geophys. Res., 116(D21), D21107, doi:10.1029/2011JD016542.

Marx, A., H. Kunstmann, D. Schüttemeyer, and A. F. Moene (2008), Uncertainty analysis for satellite derived sensible heat fluxes and scintillometer measurements over Savannah environment and comparison to mesoscale meteorological simulation results, Agr. Forest Meteorol., 148(4), 656-667.

McCabe, M. F., and E. F. Wood (2006), Scale influences on the remote estimation of evapotranspiration using multiple satellite sensors, Remote Sens. Environ., 105(4), 271-285.

Melesse, A. M., and V. Nangia (2005), Estimation of spatially distributed surface energy fluxes using remotely sensed data for agricultural fields, Hydrol. Processes, 19(14), 2653-2670.

Mohamed, Y. A., W. G. M. Bastiaanssen, and H. H. G. Savenije (2004), Spatial variability of evaporation and moisture storage in the swamps of the upper Nile studied by remote sensing techniques, J. Hydrol., 289(1-4), $145-164$.

Mohamed, Y. A., W. G. M. Bastiaanssen, and B. J. J. M. van den Hurk (2006), New lessons on the Sudd hydrology learned from remote sensing and climate modeling, Hydrol. Earth Syst. Sci., 10(4), 507-518.

Moran, M. S., T. R. Clarke, Y. Inoue, and A. Vidal (1994), Estimating crop water-deficit using the relation between surface-air temperature and spectral vegetation index, Remote Sens. Environ., 49(3), 246-263.

Nishida, K., R. R. Nemani, S. W. Running, and J. M. Glassy (2003), An operational remote sensing algorithm of land surface evaporation, $J$. Geophys. Res. Atmos., 108(D9), 4270.

Norman, J. M., W. P. Kustas, and K. S. Humes (1995), A two-source approach for estimating soil and vegetation energy fluxes in observations of directional radiometric surface-temperature, Agric. Forest Meteorol., $77(3-4), 263-293$.

Norman, J. M., M. C. Anderson, W. P. Kustas, A. N. French, J. Mecikalsi, R. Torn, G. R. Diak, T. J. Schmugge, and B. C. W. Tanner (2003), Remote sensing of surface energy fluxes at 10(1)-m pixel resolutions, Water Resour. Res., 39(8), 1221, doi:10.1029/2002WR001775.

Norman, J. M., M. C. Anderson, and W. P. Kustas (2006), Are singlesource, remote sensing surface flux models too simple?, paper presented at Earth Observation for Vegetation Monitoring and Water Management meeting, Naples, Italy, 10-11 November 2005, American Institute of Physics, Melville, N. Y., pp.170-177.

Oberg, J. W., and A. M. Melesse (2006), Evapotranspiration dynamics at an ecohydrological restoration site: An energy balance and remote sensing approach, J. Am. Water Resour. Assoc., 42(3), 565-582.

Paulson, C. A. (1970), The mathematical representation of wind speed and temperature profiles in the unstable atmospheric surface layer, J. Appl. Meteorol., 9(6), 857-861.

Pelgrum, H., and W. G. M. Bastiaanssen (1996), An intercomparison of techniques to determine the area-averaged latent heat flux from individual in situ observations: A remote sensing approach using the European field experiment in a desertification-threatened area data, Water Resour. Res., 32(9), 2775-2786.

Price, J. C. (1990), Using spatial context in satellite data to infer regional scale evapotranspiration, IEEE Trans. Geosci. Remote Sens., 28(5), 940-948.

Prueger, J. H., J. L. Hatfield, W. P. Kustas, L. E. Hipps, J. I. Macpherson, C. M. U. Neale, W. E. Eichinger, D. I. Cooper, and T. B. Parkin (2005), Tower and aircraft eddy covariance measurements of water vapor, energy, and carbon dioxide fluxes during SMACEX, J. Hydrometeorol., $6(6), 954-960$.

Ramos, J. G., C. R. Cratchley, J. A. Kay, M. A. Casterad, A. Martnez-Cob and R. Dominguez (2009), Evaluation of satellite evapotranspiration estimates using ground-meteorological data available for the Flumen District into the Ebro Valley of NE Spain, Agric. Water Manage., 96(4), 638-652.

Roerink, G. J., Z. Su, and M. Menenti (2000), S-SEBI: A simple remote sensing algorithm to estimate the surface energy balance, Phys. Chem. Earth, 25(2), 147-157.

Singh, R. K., A. Irmak, S. Irmak, and D. L. Martin (2008), Application of SEBAL model for mapping evapotranspiration and estimating surface energy fluxes in south-central Nebraska, J. Irrig. Drain. Eng., 134(3), 273-285.

Sobrino, J. A., N. Raissouni, and Z.-L. Li (2001), A comparative study of land surface emissivity retrieval from NOAA data, Remote Sens. Environ., 75(2), 256-266.

Stisen, S., I. Sandholt, A. Nørgaard, R. Fensholt, and K. H. Jensen (2008), Combined the thermal inertia- and triangle method to estimate regional evapotranspiration-Applied to MSG-SEVIRI data in the Senegal River basin, Remote Sens. Environ., 112(3), 1242-1255.

Sun, Z., M. Gebremichael, J. Ardö, and H. A. R. de Bruin (2010), Mapping daily evapotranspiration and dryness index in the East African highlands using MODIS and SEVIRI data, Hydrol. Earth Syst. Sci. Discuss., 7(4), 6285-6303.

Tang, R. L., Z.-L. Li, and B. Tang (2010), An application of the Ts-VI triangle method with enhanced edges determination for evapotranspiration estimation from MODIS data and semi-arid regions: Implementation and validation, Remote Sens. Environ., 114(3), 540-551.

Tasumi, M. (2003), Progress in operational estimation of regional evapotranspiration using satellite imagery, Ph.D. thesis, Univ. of Idaho, Moscow, Idaho.

Tasumi, M., R. G. Allen, and R. Trezza (2008), At-surface reflectance and albedo from satellite for operational calculation of land surface energy balance, J. Hydrol. Eng., 13(2), 51-63.

Teixeira, A., W. G. M. Bastiaanssen, M. D. Ahmad, and M. G. Bos (2009), Reviewing SEBAL input parameters for assessing evapotranspiration and 
water productivity for the low-middle Sao Francisco River basin, Brazil Part A: Calibration and validation, Agric. Forest Meteorol., 149(3-4), $462-476$.

Timmermans, W. J., W. P. Kustas, M. C. Anderson, and A. N. French (2007), An intercomparison of the surface energy balance algorithm for land (SEBAL) and the two-source energy balance (TSEB) modeling schemes, Remote Sens. Environ., 108(4), 369-384.

Twine, T. E., W. P. Kustas, J. M. Norman, D. R. Cook, and P. R. Houser (2000), Correcting eddy-covariance flux underestimates over a grassland, Agric. Forest Meteorol., 103(3), 279-300.

Wan, Z. M., and Z. L. Li (1997), A physics-based algorithm for retrieving land-surface emissivity and temperature from EOS/MODIS data, IEEE Trans. Geosci. Remote Sens., 35(4), 980-996.

Wang, J., T. W. Sammis, V. P. Gutschick, M. Gebremichael, and D. R. Miller (2009), Sensitivity analysis of the surface energy balance algorithm for land (SEBAL), T. ASABE, 52(3), 801-811.

Webb, E. K. (1970), Profile relationships: The log-linear range, and extension to strong stability, Q. J. R. Meteorol. Soc., 96(407), 67-90.
Wu, C. D., C.-C. Cheng, H.-C. Lo, and Y.-K. Chen (2010), Application of SEBAL and Markov models for future stream flow simulation through remote sensing, Water Resour. Manage., 24(14), 3773-3797.

Yao, W., M. Han, and S. Xu (2010), Estimating the regional evapotranspiration in Zhalong wetland with the two-source energy balance (TSEB) model and Landsat7/ETM+ images, Ecol. Inform., 5(5), 348-358.

Zwart, S. J., and W. G. M. Bastiaanssen (2007), SEBAL for detecting spatial variation of water productivity and scope for improvement in eight irrigated wheat systems, Agric. Water Manage., 89(3), 287-296.

Zwart, S. J., W. G. M. Bastiaanssen, C. De Fraiture, and D. J. Molden (2010), WATPRO: A remote sensing based model for mapping water productivity of wheat, Agric. Water Manage., 97(10), 1628-1636.

D. Long, Department of Biological and Agricultural Engineering, Texas A\&M University, College Station, TX 77843, USA. (descartes66@tamu.edu) V. P. Singh, Department of Civil and Environmental Engineering, Scoates Hall 321, Texas A\&M University, College Station, TX 77843, USA. (vsingh@tamu.edu) 